\title{
Medicinal Plants Against Coronavirus (SARS-COV-2) in Morocco Via Computational Virtual Screening Approach
}

Mohamed CHEBAIBI ( $\sim$ mohamed.chebaibi@usmba.ac.ma )

Sidi Mohamed Ben Abdellah University

Dalila Bousta

Sidi Mohamed Ben Abdellah University

Rene Francisco Boschi Gonçalves

Instituto Tecnológico de Aeronáutica

Hasnae Hoummani

Sidi Mohamed Ben Abdellah University

Sanae Achour

Sidi Mohamed Ben Abdellah University

\section{Research Article}

Keywords: COVID19, 6LU7 protease, 6Y2E protease, Moroccan plants, computational virtual screening, MD simulmation

Posted Date: July 15th, 2021

DOI: https://doi.org/10.21203/rs.3.rs-679827/v1

License: (c) (i) This work is licensed under a Creative Commons Attribution 4.0 International License. Read Full License 
Medicinal plants against coronavirus (SARS-COV-2) in Morocco via computational virtual screening approach

Mohamed Chebaibi ${ }^{1 *}$, Dalila Bousta ${ }^{2}$, Rene Francisco Boschi Gonçalves ${ }^{3}$, Hasnae Hoummani ${ }^{1}$, Sanae Achour ${ }^{1,4}$

1. Biomedical and translational research laboratory, Faculty of Medicine and Pharmacy of the Fez, University of Sidi Mohamed Ben Abdellah, BP 1893, Km 22, Road of Sidi Harazem, Fez, Morocco

2. Laboratory of Neuroendocrinology and Nutritional and Climatic Environment, FSDM, University of Sidi Mohamed Ben Abdellah, Fez,Morocco

3. Aeronautics Institute of Technology Praça Marechal Eduardo Gomes, 50 São José dos Campos/SP Brazil Zip Code: 12228-900

4. Laboratory of pharmacology and toxicology, University Hospital Hassan II-Fez, Fez, Morocco

* Corresponding author.

E-mail address: Mohamed.chebaibi@yahoo.fr

\section{Abstract}

With the spread of the coronavirus in all countries of the world and in the absence of a vaccine or effective treatment to inhibit the infection. Several medicinal plants are used by the Moroccan population either to treat or prevent infection. The frequent use of its plants without documentation of their effectiveness on the Covid-19 is justified by cultural and economic reasons and their pharmacological activity scientifically proven. The objective of this study is to evaluate the inhibitory effect of the main polyphenols and flavonoids of Syzygium aromaticum and citrus limon as well as the main organosulfur compounds of garlic against coronavirus 6lu 7 protease and 6y2e protease using in-silico molecular docking analysis.

The COVID-19 3CLpro/Mpro (PDB ID: 6LU7) and free enzyme of the SARS-CoV-2 (2019- nCoV) main protease (PBD ID: 6Y2E) structures were obtained from the https://www.rcsb.org/ website in .PDB format. The COVID-19 3CLpro/Mpro (PDB ID: 6LU7) and main protease (PBD ID: 6Y2E) were prepared using autodock tools from MGL Tools package http://mgltools.scripps.edu/.

The reactive molecular dynamics simulations were performed using the software LAMMPS and the 
ReaxFF force field. In this force field, the general energy function

We have docked 34 natural products belonging to the three medicinal plants. In 6LU7 protease, 24 compounds exhibited a binding affinity greater than or equal to $-6 \mathrm{Kcal} / \mathrm{mol}$. While, in $6 \mathrm{Y} 2 \mathrm{E}$ protease, 6 compounds exhibited a binding affinity greater than or equal to $-6 \mathrm{Kcal} / \mathrm{mol}$.

We found that ellagic acid, narirutin, neoeriocitrin and neohesperidin are highly suggested as an inhibitor of SARS-COV-2.

Keywords: COVID19, 6LU7 protease, 6Y2E protease, Moroccan plants, computational virtual screening, MD simulmation. 


\section{Graphical abstract}
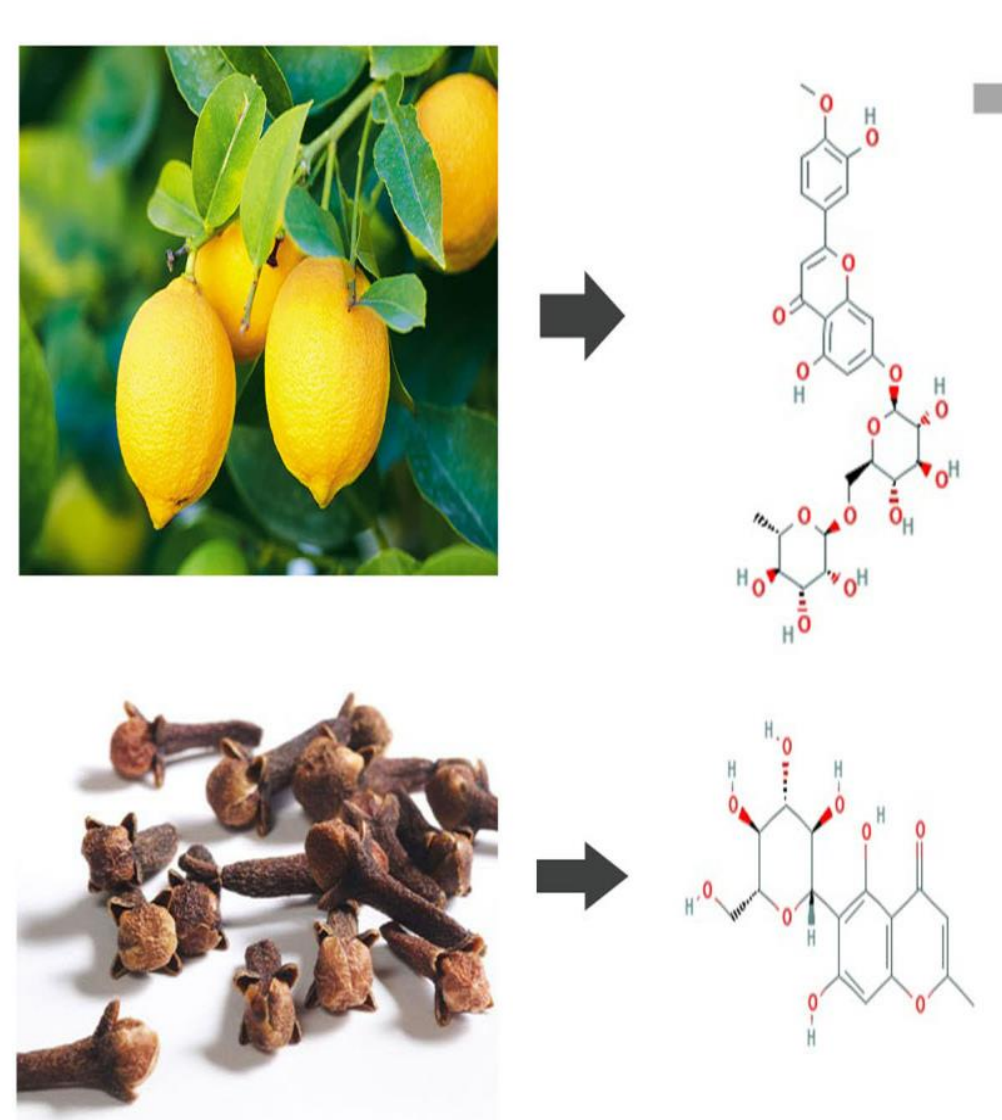

Molecular docking
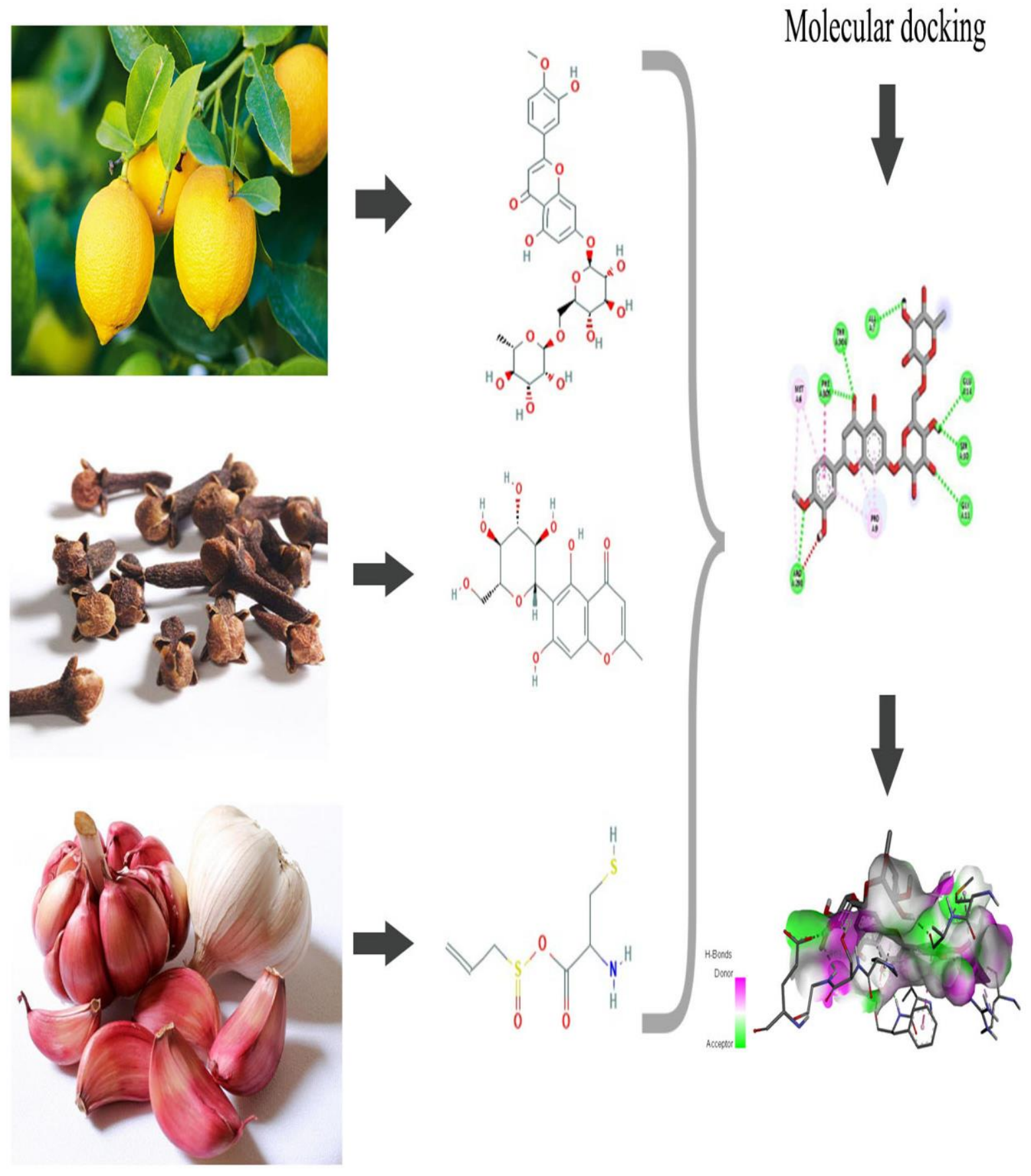


\section{Introduction}

COVID-19 is the infectious disease caused by the last coronavirus that was discovered. This new virus and disease were unknown before the outbreak occurred in Wuhan, China in December 2019. COVID-19 is now pandemic and affects many countries around the world with more than 31,000,000 infections and more than 970,000 death.

In the absence of an effective vaccine against this virus, several studies have been done to examine the inhibitory effect of natural bioactive molecules on papain-like protease (PLpro) and 3chymotrypsin-like protease $\left(3 \mathrm{CL}^{\mathrm{pro}}\right.$ ) using molecular docking analysis to arrive at binding affinity (Aanouz et al., 2020; Khaerunnisa, Kurniawan, Awaluddin, Suhartatiand Soetjipto, 2020; ul Qamar, Alqahtani, Alamriand Chen, 2020). 3CL pro plays an important role in the replication of viral particles, it is a potential target for anti-coronaviruses inhibitors screening (ul Qamar et al., 2020). While, $\mathrm{Pl}^{\text {pro }}$ is an essential coronavirus enzyme that is required for processing viral polyproteins to generate a functional replicase complex and enable viral spread (Shin et al., 2020).

In Morocco, more than 100.000 cases of coronavirus confirmed and more than 1,800 cases of death. In front of this pandemic situation, several medicinal plants are used by the Moroccan population either to treat or prevent infection. The frequent use of its plants without documentation of their effectiveness on the Covid-19 is justified by cultural and economic reasons and their pharmacological activity scientifically proven.

We carried out a survey on the medicinal plants used by the Moroccan population to treat or prevent covid19 and we found the massive use of three plants (garlic, citrus limon and clove). Garlic is widely used for the treatment of viral infections due to the presence of several bioactive molecules such as allicin, diallyl trisulfide and ajoene. The antiviral effect of garlic extract has been shown against rhinovirus, HIV, herpes simplex virus 1 (Tsai et al., 1985), against herpes simplex virus 2 (Weber et al., 1992), influenza A and B (Fenwick and Hanley, 1985), cytomegalovirus, viral pneumonia, and rotavirus (Bayan, Koulivandand Gorji, 2014). Citrus limon another plant used by the Moroccan population to prevent the covid-19 pandemic. This plant rich in flavonoids such as diosmin, eriocitrin and hesperidin. some authors suggest that these flavonoids have several biological activities like antiviral activities (Del Rio et al., 2004).

The antiviral activity of eugeniin extracted from clove has been reported against herpes virus and it was deducted that one of the major targets of eugeniin is the viral DNA synthesis by the inhibition of the viral DNA polymerase (Cortés-Rojas, de Souzaand Oliveira, 2014). Moreover, eugenol is one major constituent of cloves has shown antiviral activity against human herpes simplex (Aboubakr et al., 2016). 
The objective of this study is to evaluate the inhibitory effect of the main polyphenols and flavonoids of Syzygium aromaticum and citrus limon as well as the main organosulfur compounds of garlic against covid-19 6lu7 protease and 6y2e protease using in-silico molecular docking analysis.

2. Materials and Methods

2.1.Data sets

The COVID-19 3CL pro/M pro (PDB ID: 6LU7) and free enzyme of the SARS-CoV-2 (2019- nCoV) main protease (PBD ID: 6Y2E) structures were obtained from the https://www.rcsb.org/website in .PDB format.

The 3D structures of the selected ligands were obtained from the https://pubchem.ncbi.nlm.nih.gov/ website in the .SDF format. Then they optimized by ucsf chimera 1.14 software from https://www.cgl.ucsf.edu/chimera/ and saved in .MOL2 format. Table 1 presents the main bioactive molecules of each plant, their pubchem ID and their structures.

\subsection{Molecular docking}

The COVID-19 3CL $\mathrm{C}^{\text {pro }} / \mathrm{M}^{\text {pro }}$ (PDB ID: 6LU7) and main protease (PBD ID: 6Y2E) were prepared using autodock tools from MGL Tools package http://mgltools.scripps.edu/. The water molecules and het atoms have been removed and the polar hydrogen were added. The native position of the ligand on the binding site was determined by Autogrid using the default settings ( $\mathrm{x}=$ 26,283, $y=12,599, z=58,965$ at 1 Angstrom spacing). Ligand tethering of the protein was performed by genetic algorithm (GA) parameters, using 100 runs of the GA criteria. Then Autodock vina was used to stimulate bioactive conformation. The results were analyzed by Biovia Discovery studio client 2020(Dassault Systèmes BIOVIA, Discovery Studio Modeling Environment, Release 2017, San Diego: Dassault Systèmes, 2016).

Table 1: Bioactive molecules of syzygium aromaticum, citrus limon and allium sativum and their pubchem ID and their structures

\begin{tabular}{|l|l|l|l|l|}
\hline Plants & Compounds & CID & Structure & formula \\
\hline $\begin{array}{l}\text { Syzygium } \\
\text { aromaticum }\end{array}$ & Biflorin & 441459 & & \\
& & & &
\end{tabular}




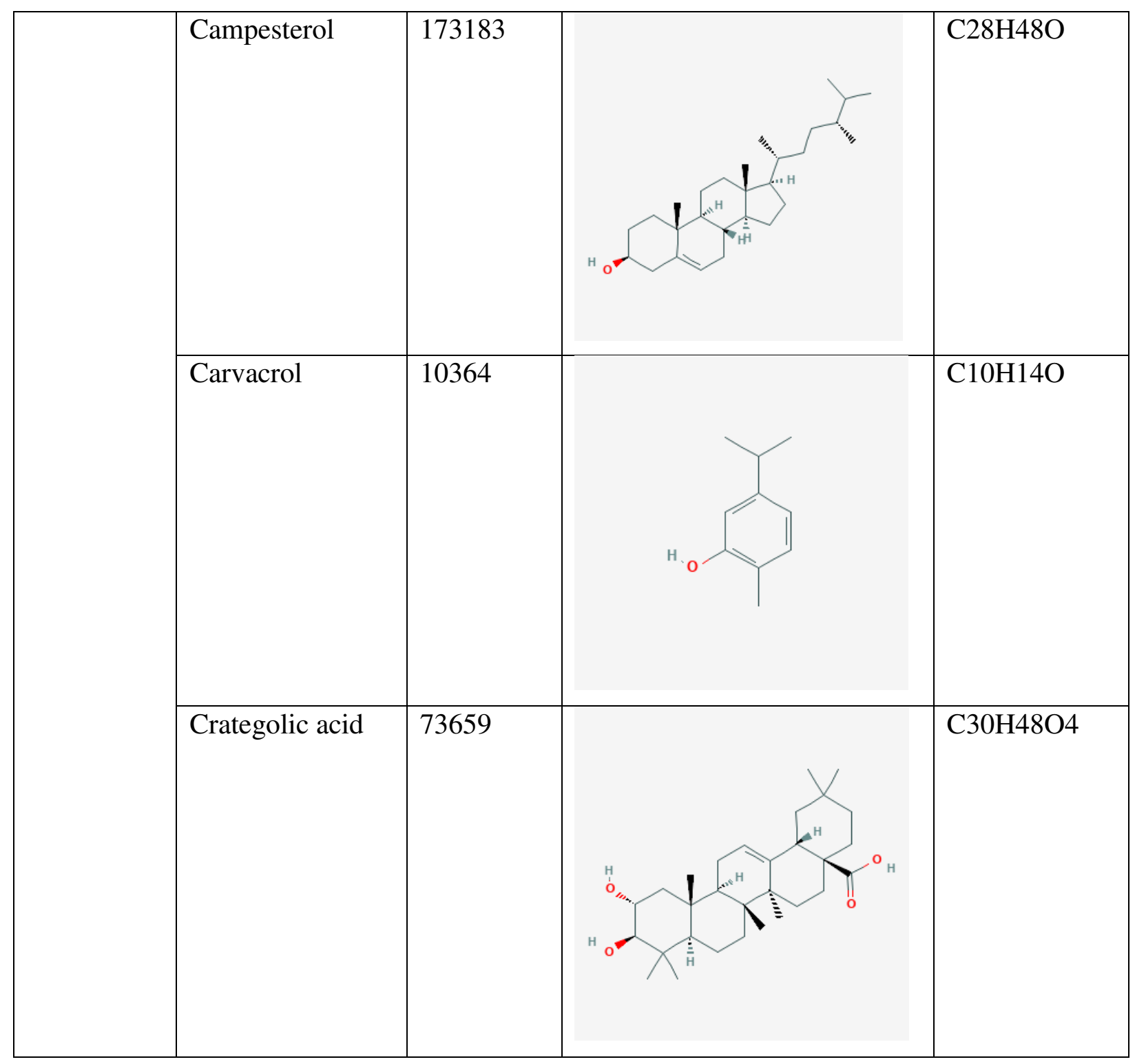




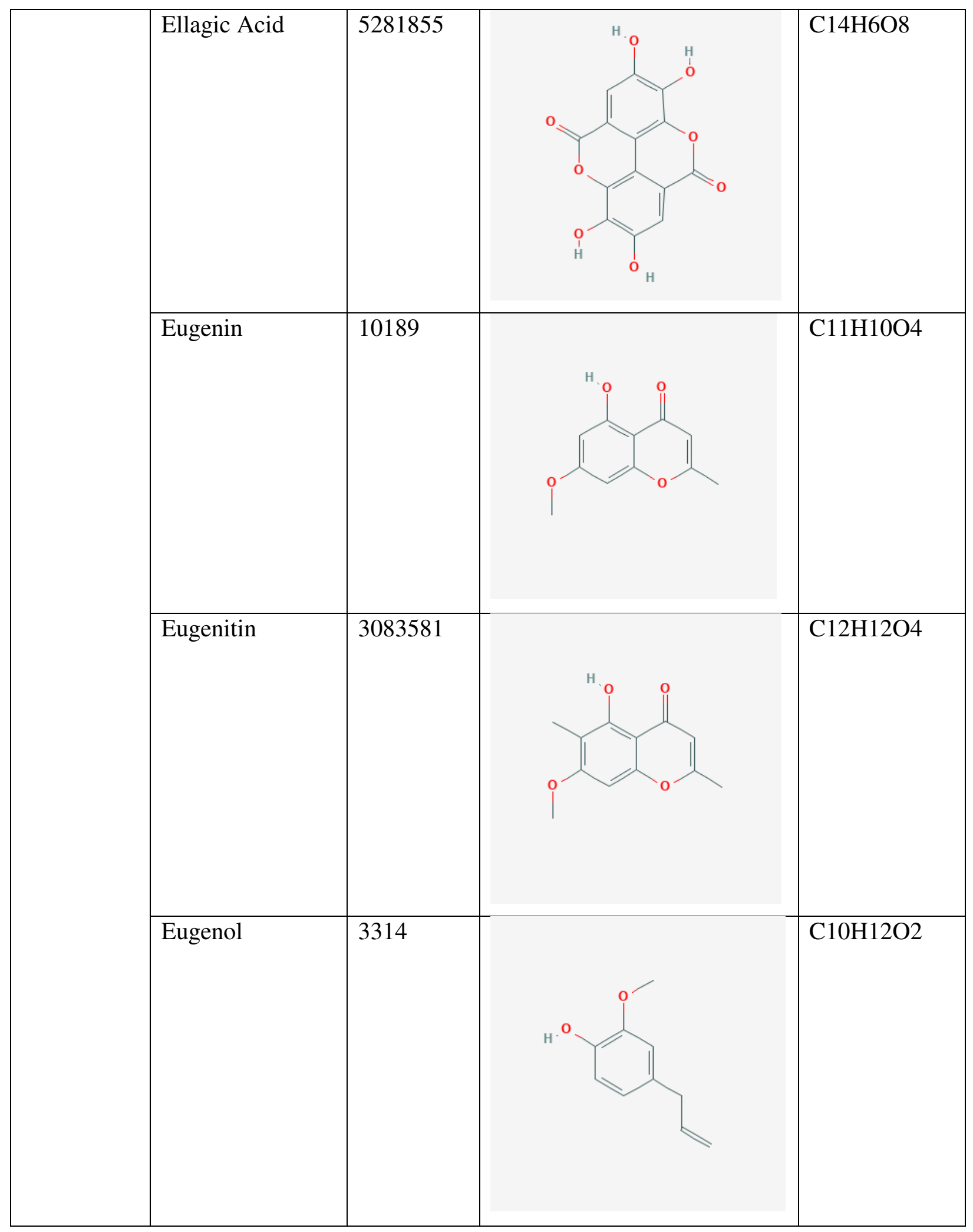




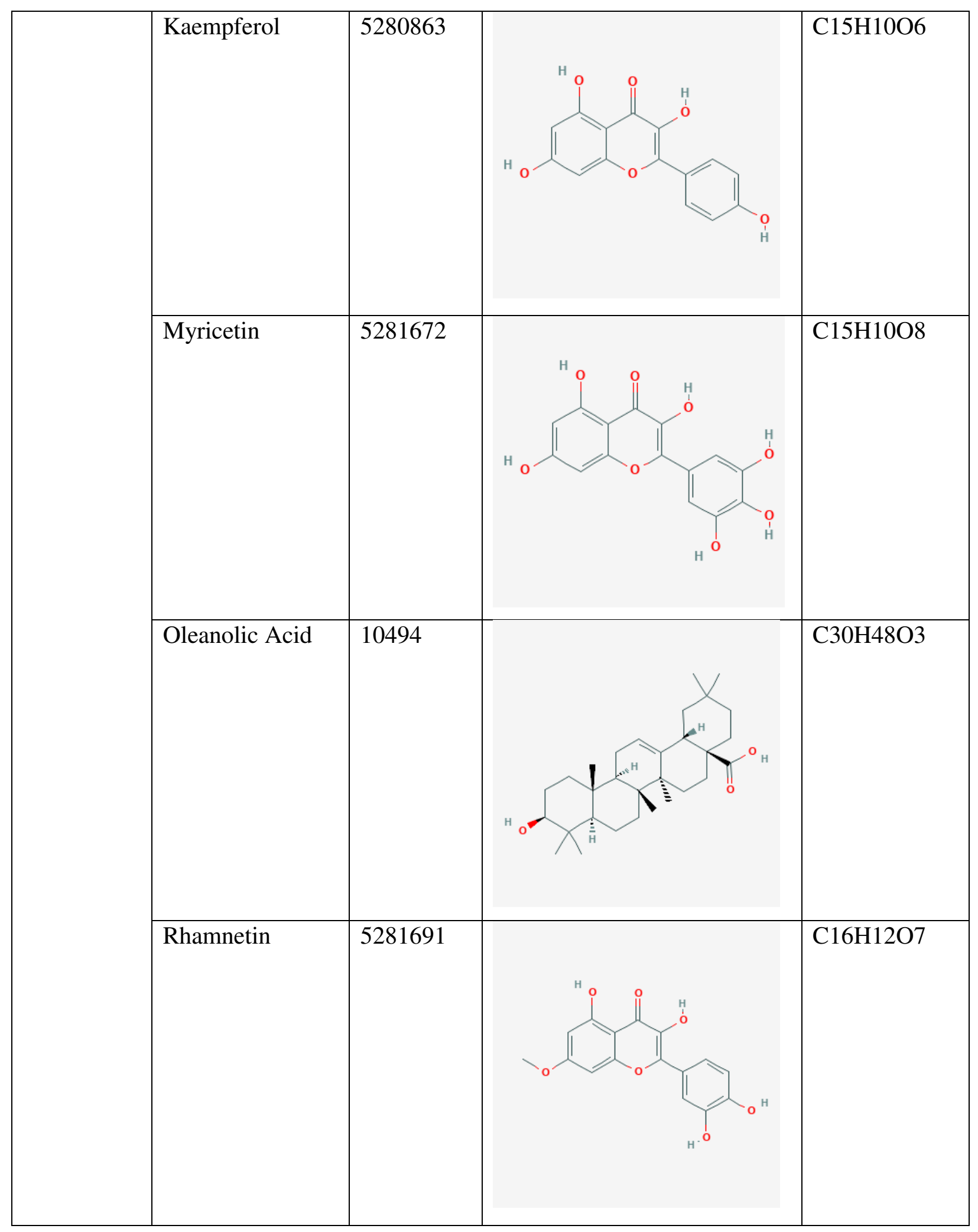




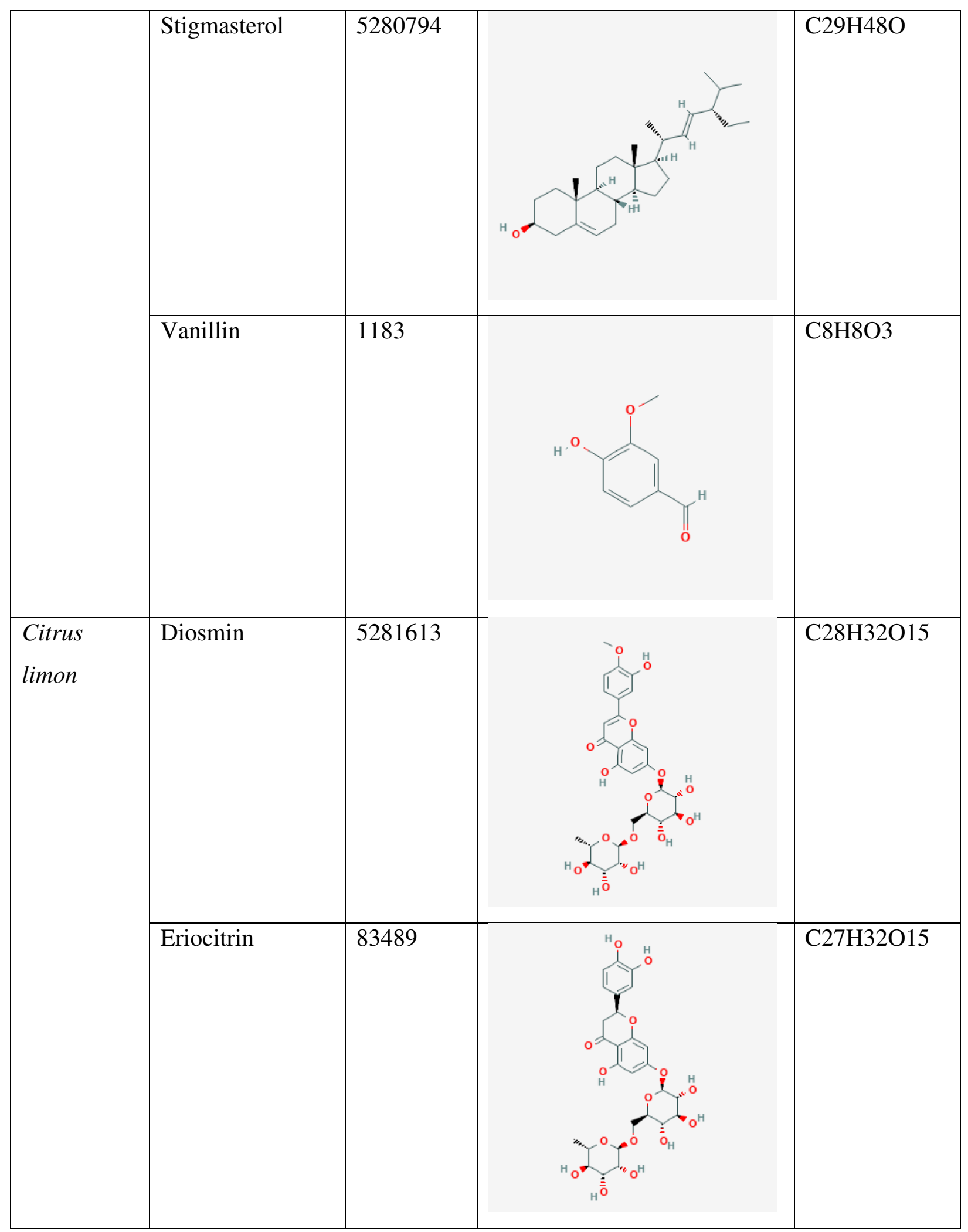




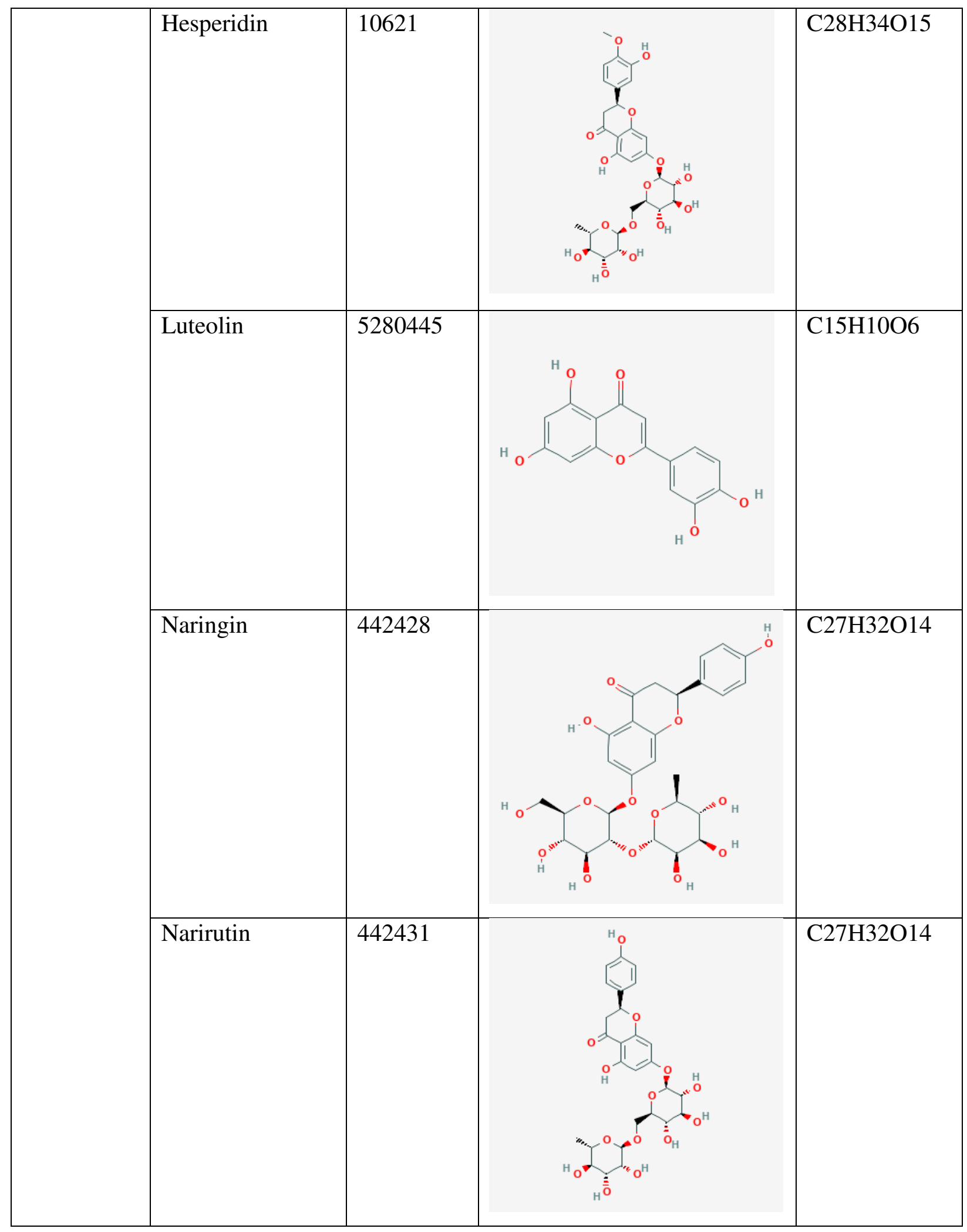




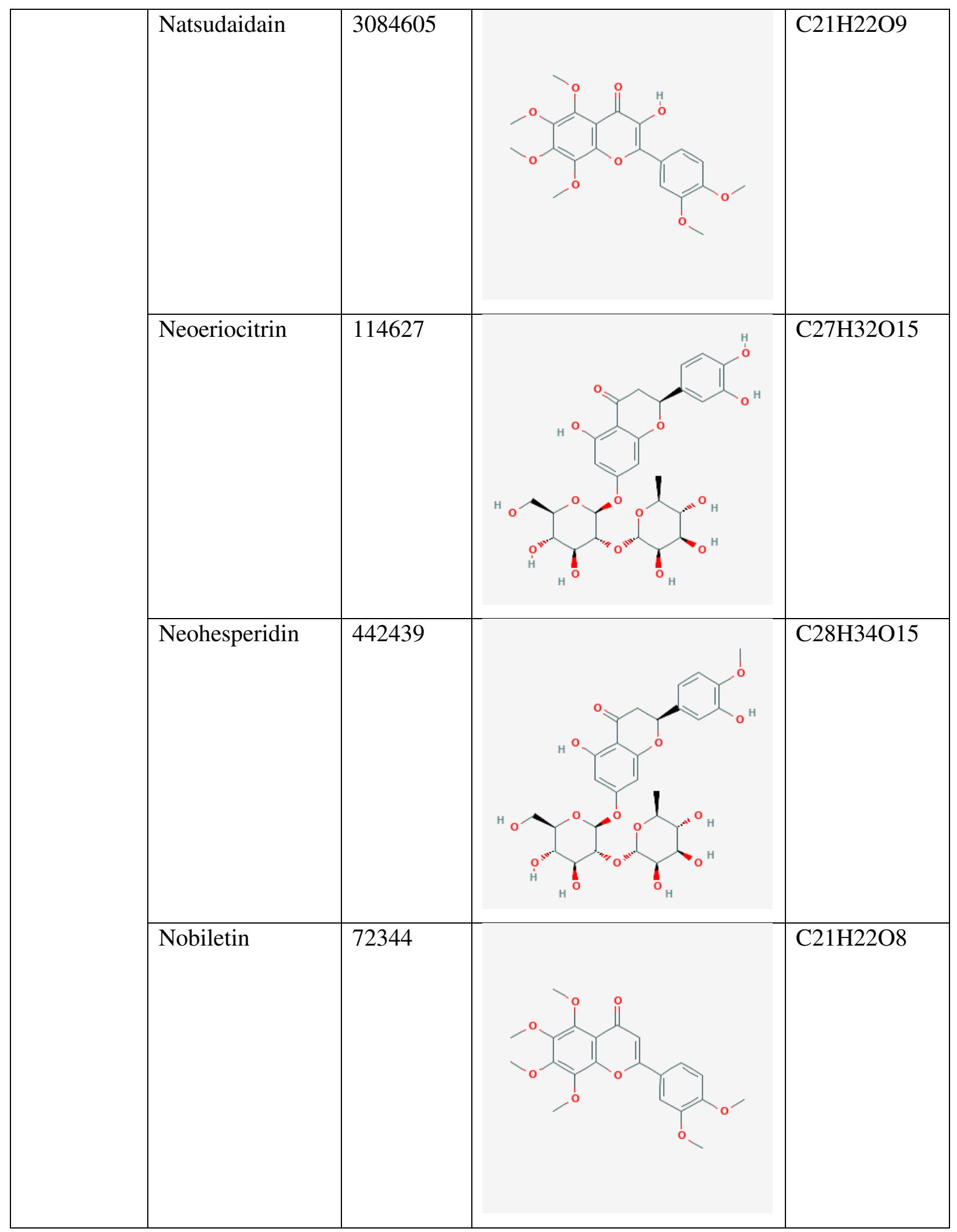




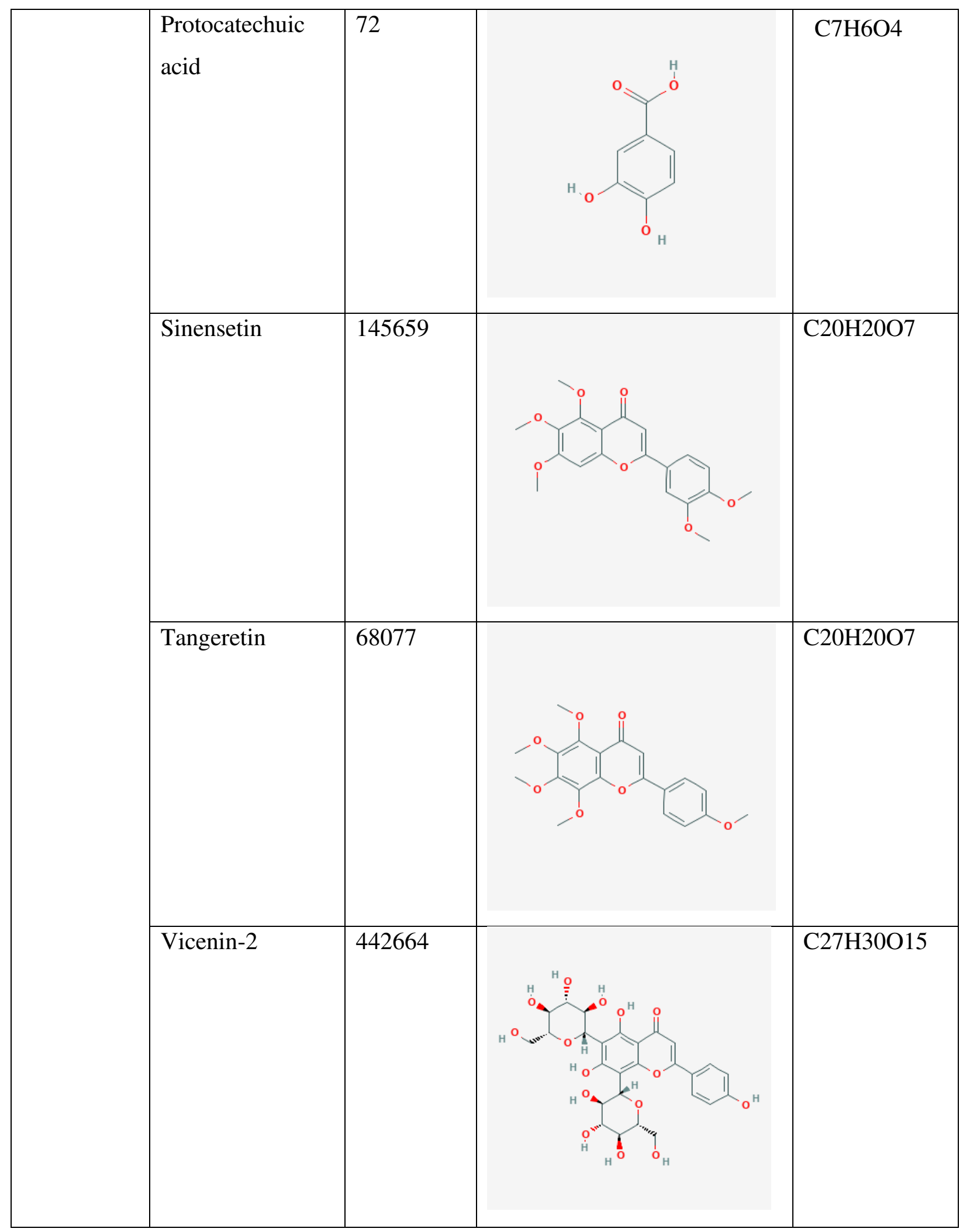




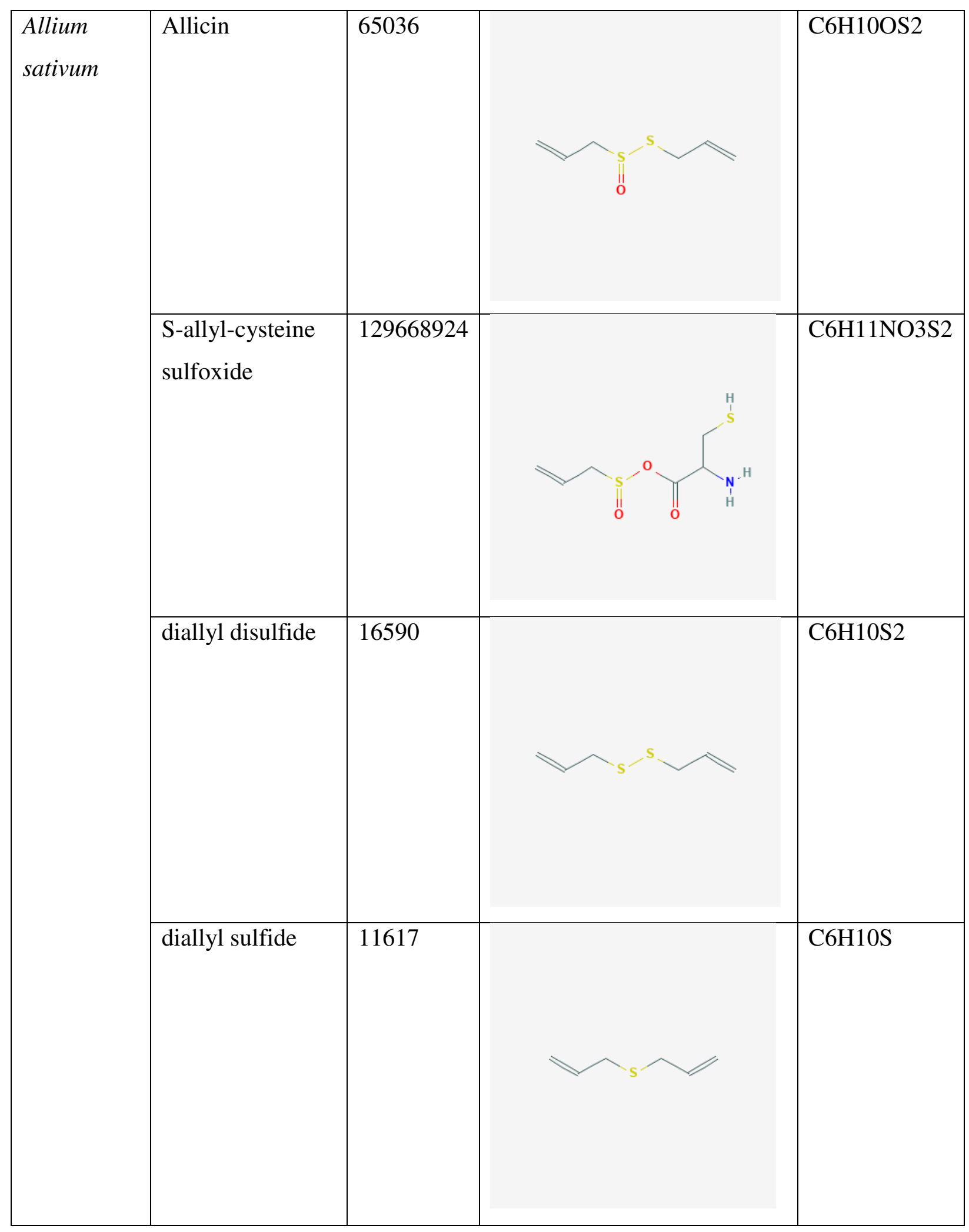




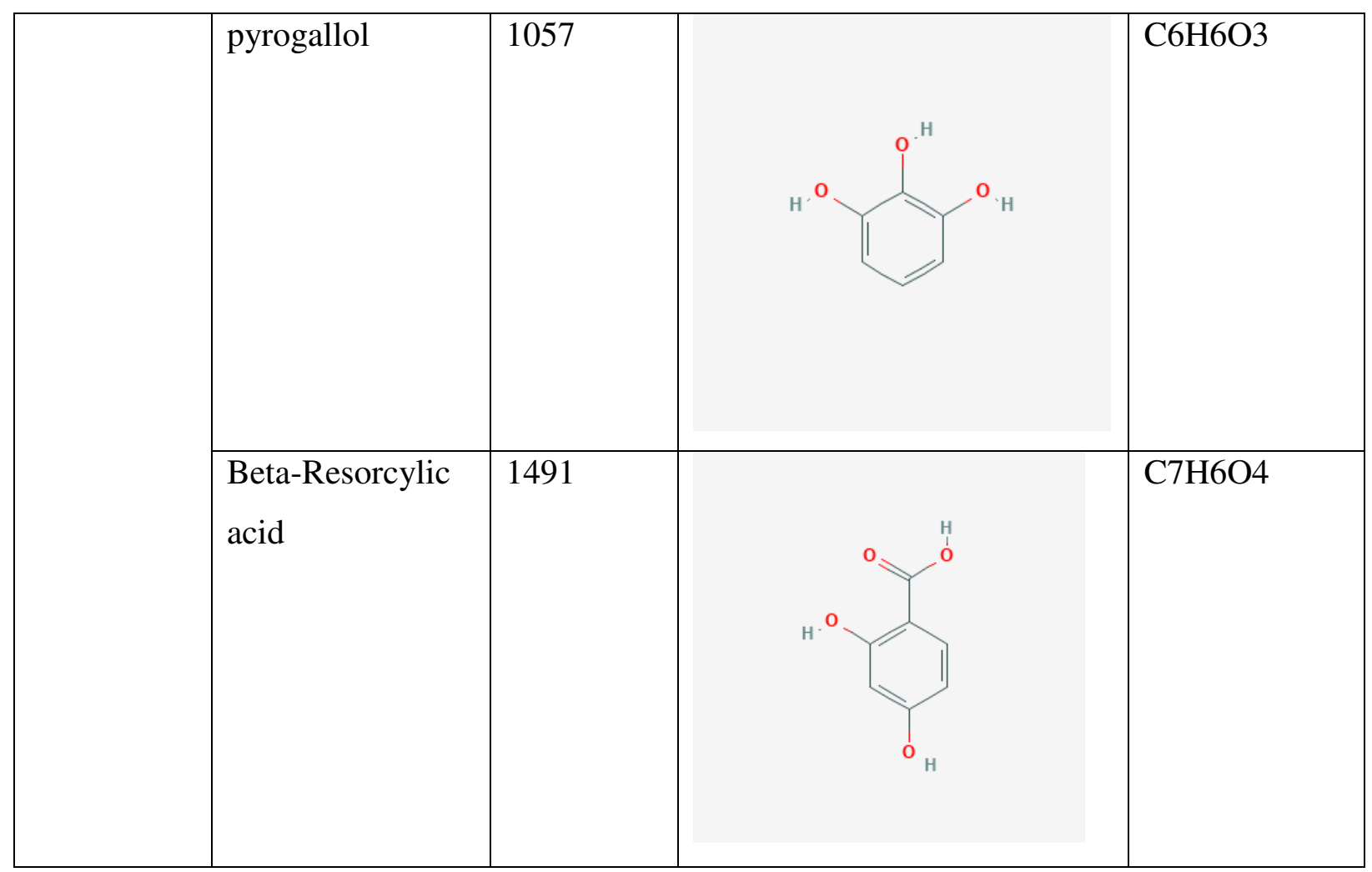

\subsection{Molecular Dynamic simulation}

The reactive molecular dynamics simulations were performed using the software LAMMPS (Large-scale Atomic/Molecular Massively Parallel Simulator) and the ReaxFF force field. In this force field, the general energy function takes the following formulation:

$$
E_{\text {system }}=E_{\text {bond }}+E_{\text {over }}+E_{\text {under }}+E_{\text {val }}+E_{\text {pen }}+E_{\text {tors }}+E_{\text {conj }}+E_{\text {vdWaals }}+E_{\text {Coulomb }}
$$

where:

- $E_{\text {bond }}$ represents the bond energy;

- $E_{\text {over }}$ and $E_{\text {under }}$ denotes the over- and under-coordinated atom in the energy contribution, respectively;

- $E_{\text {val }}, E_{\text {pen }}, E_{\text {tors }}$ are the valence angle term, penalty energy and torsion energy, respectively;

- $E_{c o n j}, E_{v d W a a l s}, E_{C o u l o m b}$ represent the conjugation effects to molecular energy, nonbonded van der Waals interaction and Coulomb interaction, respectively.

At every MD (Molecular Dynamics) step, this force field updates the bond orders and provides a pathway for bonds to form and break during the simulation. ReaxFF can reproduce with acuity all relevant quantum mechanical data, as well as provide atomistic descriptions of several complex chemical reactions. 
The simulations were done using the target ligands close to the protein structure, maintained at a constant temperature of $298 \mathrm{~K}$. In MD simulations, temperature is set based on the displacement velocities of each atom/molecule. ReaxFF forcefield was applied with a timestep of $0.1 \mathrm{fs}$, so every interaction and bond could be observed during the simulation.

Reactions involving protein + ligand systems usually require a high amount of time. The total number of iteractions used in these simulations were $25 \mathrm{M}$, thus representing a timeframe of $2.5 \mathrm{~ns}$. Although it may seem small, common methods of MD applied in these systems (e.g. CHARMM forcefield) use timesteps of $2 \mathrm{fs}, 8$ times higher than the one used in ReaxFF, so the timeframe of both methods can be equated. The calculation time of each simulation was around 700 hours.

ReaxFF is not commonly used in these systems, as it was originally built for analyzing fast reactions or complex mechanisms. However, due to the usage of bond orders for determining the energies, it can be an interesting methodology for analyzing interactions between large structures and ligands. Physical interactions or chemical bonds can be observed and thus the behavior of the ligand and the overall binding energy/stabilization of the system can be predicted.

Four different systems (protein + ligand) were chosen for the simulations:

- Case 1: 6lu7 + Hesperidin;

- Case 2: 6y2e + Hesperidin;

- Case 3: 6lu7 + Diosmin;

- Case 4: 6y2e + Diosmin.

The system was minimized using low temperature $(5 \mathrm{~K})$ molecular dynamics. After minimization, for the equilibration phase, the NVT ensemble (canonical, with constant number of atoms, volume and temperature) was used, and for the production phase, the NVE ensemble was employed (constant number of atoms (N), constant volume (V) and control of the potential energy (E)). The temperatures were controlled by the Berendsen thermostat, with temperature damping constant of $50 \mathrm{fs}$. Fig. 1 below presents the temperature variation during the simulations. 


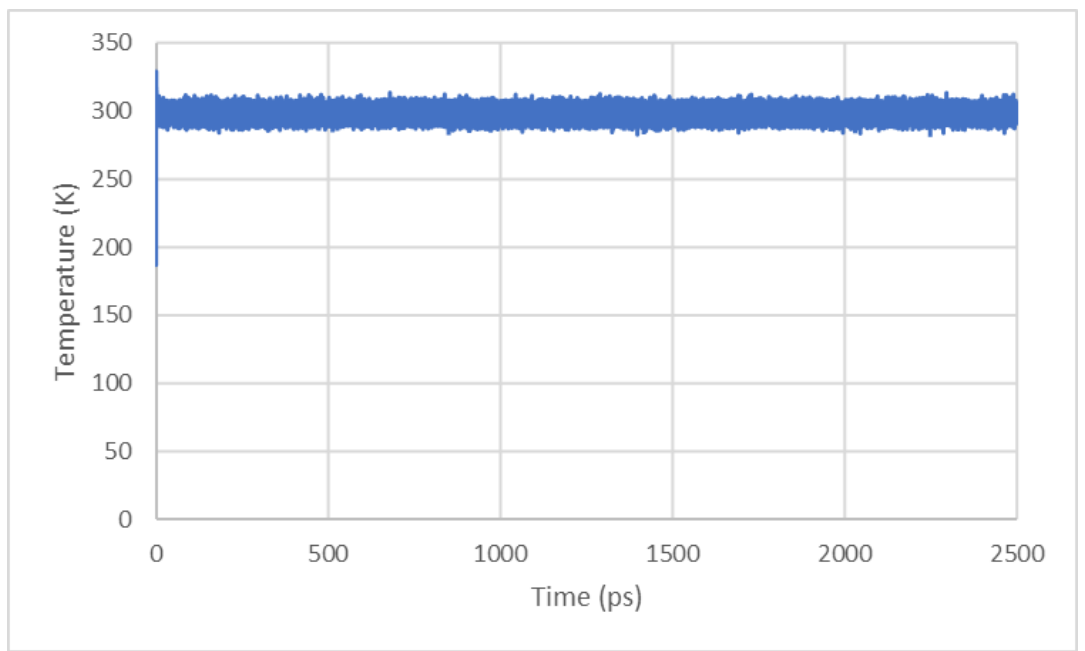

Figure 1. Temperature variation during simulations

\section{Results and discussion}

In total, we have docked 34 natural products belonging to the three medicinal plants. Table 2 shows binding affinity between natural compounds and the 6LU7 and 6Y2E proteases. In 6LU7 protease, 24 compounds exhibited a binding affinity greater than or equal to $-6 \mathrm{Kcal} / \mathrm{mol}$ [ $-6 \mathrm{Kcal} / \mathrm{mol}$ is the energy value of interaction of the molecule referred (Chloroquine)]. The ellagic Acid, narirutin, neoeriocitrin and neohesperidin at interaction energy equal to $-8.4 \mathrm{kcal} / \mathrm{mol}$. Diosmin at a value of $-7.8 \mathrm{kcal} / \mathrm{mol}$, kaempferol and hesperidin at a value of $-7.6 \mathrm{kcal} / \mathrm{mol}$, crategolic acid and oleanolic acid at a value of $7.5 \mathrm{kcal} / \mathrm{mol}$ and luteolin and naringin at a value of $-7.4 \mathrm{kcal} / \mathrm{mol}$.

Table2: Binding affinity between natural compounds and the 6LU7 and 6Y2E proteases

\begin{tabular}{|l|l|l|}
\hline Compound name & $\begin{array}{l}\text { Binding affinity (Kcal/mol) } \\
6 \mathrm{LU} 7 \text { protease }\end{array}$ & $\begin{array}{l}\text { Binding affinity (Kcal/mol) } \\
6 \text { Y2E protease }\end{array}$ \\
\hline Biflorin & -6.7 & -6.9 \\
\hline Campesterol & -6.8 & -5.0 \\
\hline Carvacrol & -5.2 & -4.4 \\
\hline Crategolic acid & -7.5 & -5.3 \\
\hline Ellagic Acid & -8.4 & -5.7 \\
\hline Eugenin & -6.0 & -4.9 \\
\hline Eugenitin & -6.0 & -5.0 \\
\hline
\end{tabular}




\begin{tabular}{|c|c|c|}
\hline Eugenol & -5.5 & -5.0 \\
\hline Kaempferol & -7.6 & -5.1 \\
\hline Myricetin & -6.7 & -5.1 \\
\hline Oleanolic Acid & -7.5 & -7.1 \\
\hline Rhamnetin & -7.3 & -5.2 \\
\hline Stigmasterol & -7.0 & -5.0 \\
\hline Vanillin & -5.0 & -3.4 \\
\hline Diosmin & -7.8 & -7.7 \\
\hline Eriocitrin & -8.0 & -6.0 \\
\hline Hesperidin & -7.6 & -8.1 \\
\hline Luteolin & -7.4 & -5.4 \\
\hline Naringin & -7.4 & -5.4 \\
\hline Narirutin & -8.4 & -5.8 \\
\hline Natsudaidain & -6.5 & -5.0 \\
\hline Neoeriocitrin & -8.4 & -5.5 \\
\hline Neohesperidin & -8.4 & -6.2 \\
\hline Nobiletin & -6.4 & -5.2 \\
\hline Protocatechuic acid & -5.4 & -5.0 \\
\hline Sinensetin & -6.3 & -5.2 \\
\hline Tangeretin & -6.1 & -5.0 \\
\hline Vicenin-2 & -7.5 & -2.5 \\
\hline Allicin & -3.7 & -2.8 \\
\hline S-allyl-cysteine sulfoxide & -4.3 & -4.0 \\
\hline diallyl disulfide & -2.9 & -2.5 \\
\hline diallyl sulfide & -3.0 & -2.5 \\
\hline
\end{tabular}




\begin{tabular}{|l|l|l|}
\hline Pyrogallol & -4.9 & -3.5 \\
\hline Beta-Resorcylic acid & -5.7 & -5.3 \\
\hline
\end{tabular}

Ellagic acid is a polyphenol known to be present in many medicinal plants and vegetables such as Syzygium aromaticum (Batiha et al., 2020). Antioxidant, anticarcinogenic and chemopreventive activity of ellagic acid has been shown by several studies (Ismail et al., 2016; Moktar, Ravoori, Vadhanam, Gairolaand Gupta, 2009; Narayanan, Geoffroy, Willingham, Reand Nixon, 1999). Regarding antiviral activity, ellagic acid had an IC50 value of $1.4 \mu \mathrm{M}$ and $6.4 \mu \mathrm{M}$ against Ebola virus (EBOV) and Marburg virus (MARV) pseudovirions, respectively (Cui et al., 2018). In addition, its anti-Zika activities and antihuman rhinoviruses (anti-HRV) activities have been demonstrated (Acquadro et al., 2020; Park, Kwon, Yoo, Choiand Ahn, 2014).

Narirutin, neoeriocitrin, neohesperidin, diosmin and hesperidin are the main flavanone-7-O-glycosides presented in citrus, they are known to have antioxidant, anticancer, antiviral and anti-inflammatory activities (Aturki, Brandiand Sinibaldi, 2004).

In the treatment of H1N1 infection, a study via computational virtual screening approach showed that narirutin and hesperidin had a significantly higher docking score than the currently marketed antiinfluenza drug Oseltamivir (Tamiflu) (Sharma, Tendulkarand Wangikar, 2011). Moreover, another study mentioned that hesperidin, neohesperidin and diosmin have an effect against human rotavirus (BenShabat, Yarmolinsky, Poratand Dahan, 2020).

Kaempferol, a natural flavonoid, it has several biological activities including antioxidant, antiinflammatory, antimicrobial, antidiabetic, anticancer and antiviral activities. The antiviral activity of kaempferol has been reported against human cytomegalovirus (Mitrocotsa, Mitaku, Axarlis, Harvalaand Malamas, 2000), Human immunodeficiency virus 1 (HIV-1)(Behbahani, Sayedipour, Pourazarand Shanehsazzadeh, 2014), Japanese Encephalitis Virus (JEV)(Care et al., 2020) and against coronaviruses (Schwarz et al., 2014).

Oleanolic acid is a biologically active pentacyclic triterpenoid compound, it is present in more than 1620 plants (Pollier and Goossens, 2012). Serval activities of oleanolic acid have been reported such as antioxidant (Ovesná, Kozicsand Slameňová, 2006; Somova, Shode, Ramnananand Nadar, 2003; Sultana and Ata, 2008), anticancer (Dzubak et al., 2006), anti-inflammatory (Petronelli, Pannitteriand Testa, 2009), antibacterial (Hichri, Jannet, Cheriaa, Jeghamand Mighri, 2003; Kim, Lee, Lee, Yoonand Choi, 2015) and antiviral activities (Kong et al., 2013). Concerning the antiviral activity of oleanolic acid, it is 
confirmed as anti-HIV (Zhu, Shen, Wang, Cosentinoand Lee, 2001), anti-influenza (Yu et al., 2006), antiHCV (Kong et al., 2013) and anti-HSV-1 activities (Ikeda et al., 2005).

In $6 \mathrm{Y} 2 \mathrm{E}$ protease, 6 compounds exhibited a binding affinity greater than or equal to $-6 \mathrm{Kcal} / \mathrm{mol}$. In addition to oleanolic acid, diosmin, eriocitrin hesperidin and neohesperidin which are active on the 6lu 7 site are also active on the 6y2e site with different energy between the two proteases.

Biflorin another compound extracted from Syzygium aromaticum, is a natural o-naphthoquinone known for its strong anticancer activity (de Vasconcellos et al., 2007; Montenegro, Burbano, Silva, Lemosand Vasconcellos, 2013). The antiviral activities of biflorin have been reported against dengue virus (DENV)(Saleem, Batool, Mansoor, Shahzad-ul-Hussanand Saeed, 2019).

Table 3 shows the interactions between the different bioactive molecules and 6lu7 and 6y2e protease. The presence of hydrogen bonds in the complex explains the good interaction between the molecule and the protease. Knowing that hydrogen bonds are considered first level interactions, while other types of interactions such interactions between $\mathrm{p}$ systems and cation $-\mathrm{p}$ interactions and hydrophobic contacts and non-specific Van der Waals interactions are considered second and third level interactions respectively (Aanouz et al., 2020).

In our studies, molecules with a maximum binding affinity equal to $-8.4 \mathrm{kcal} / \mathrm{mol}$ show good hydrogen bonds with $6 l u 7$ and 6y2e protease. For example, diosmin has 3 hydrogen bonds with $61 \mathrm{lu}$ protease: ILE249, GLN110, GLN107, while it is 4 hydrogen bonds with 6Y2E protease: ALA7, GLU14, SER10, GLY11, THR304, PHE305, ARG298 (Table 3 and Figure 2).

Despite the known antiviral activity of garlic, their organosulfur compounds studied in our research such as allicin, S-allyl-cysteine sulfoxide, diallyl disulfide, diallyl sulfide, diallyl trisulfide and S-allyl-cysteine present a weak band affinity which does not exceed $-4.3 \mathrm{kcal} / \mathrm{mol}$ for $6 \mathrm{lu} 7$ and 6y2e protease (Table 2). 
Table 3: Interactions between the different bioactive molecules and $61 \mathrm{u} 7$ and 6y2e protease

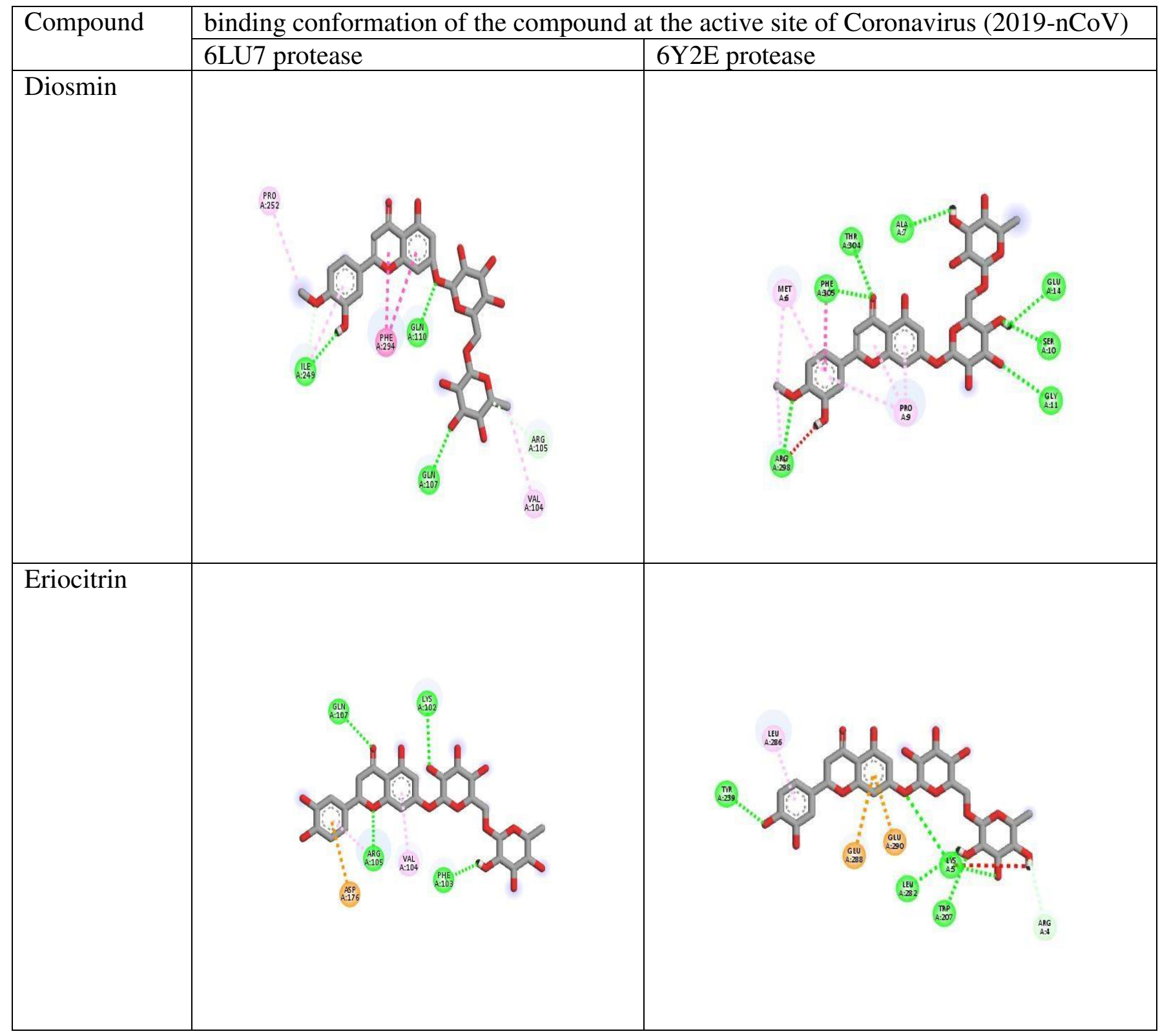




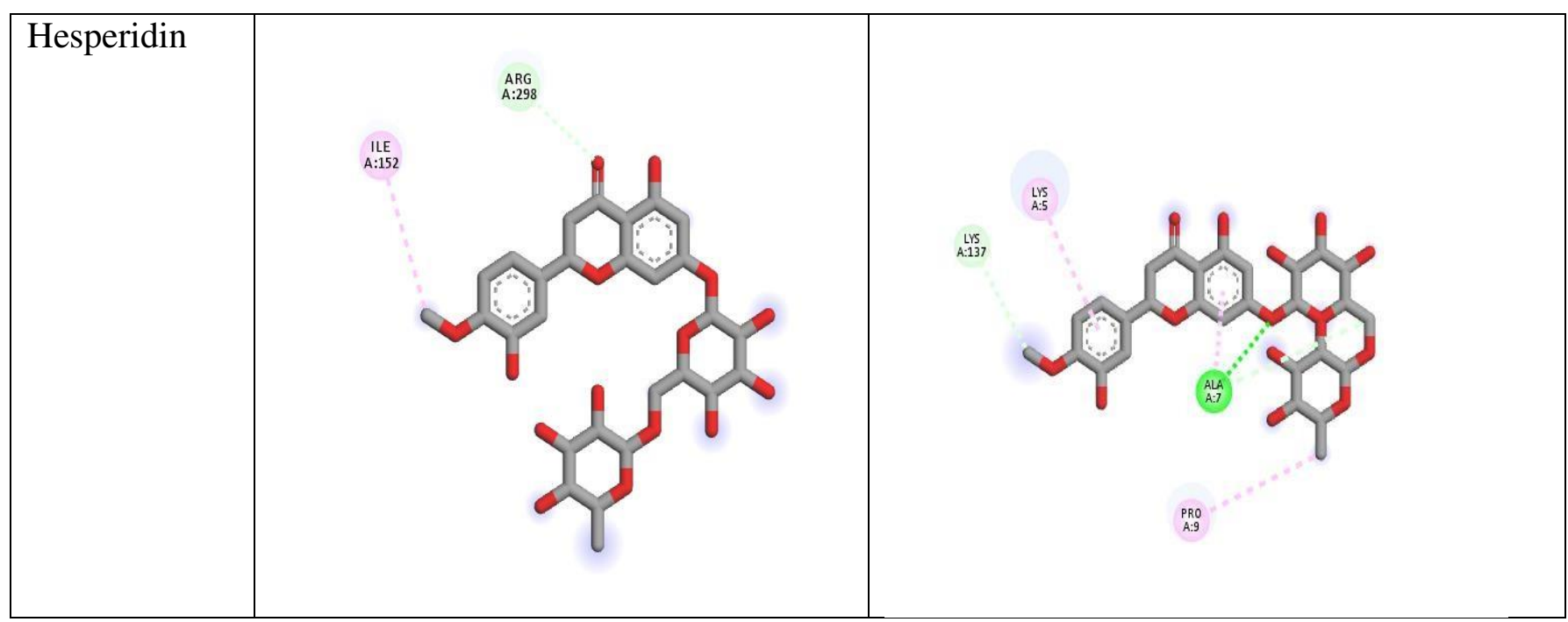




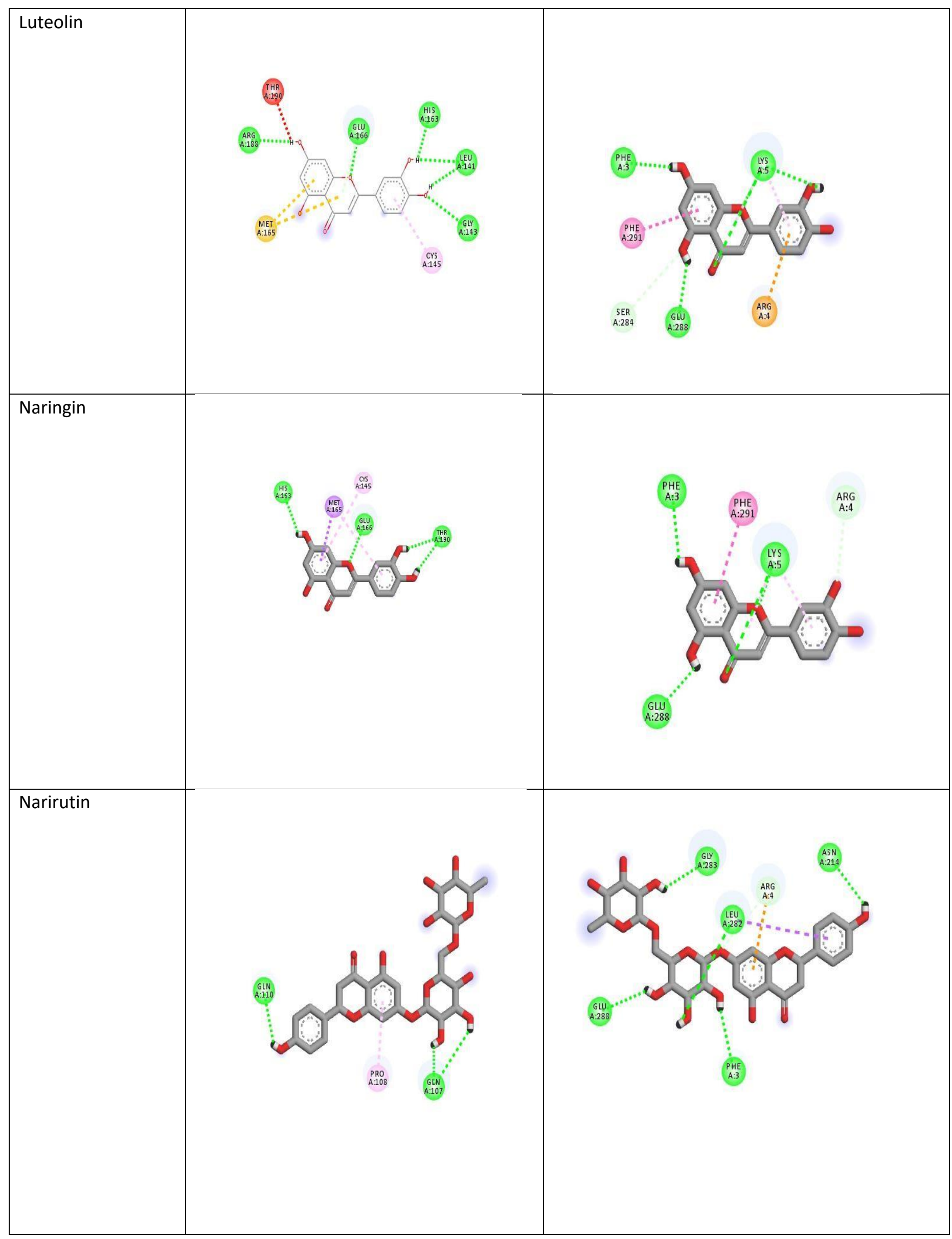




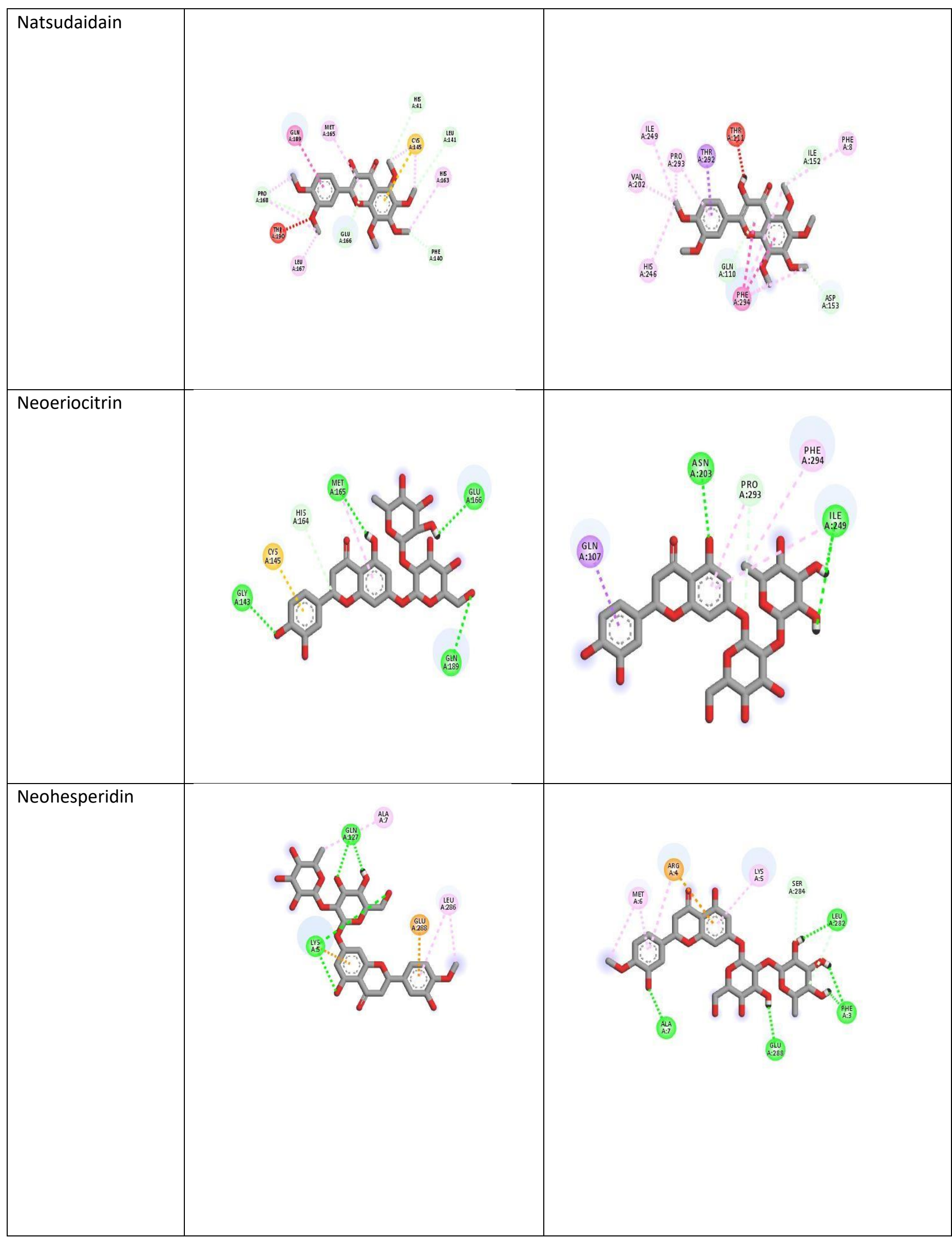




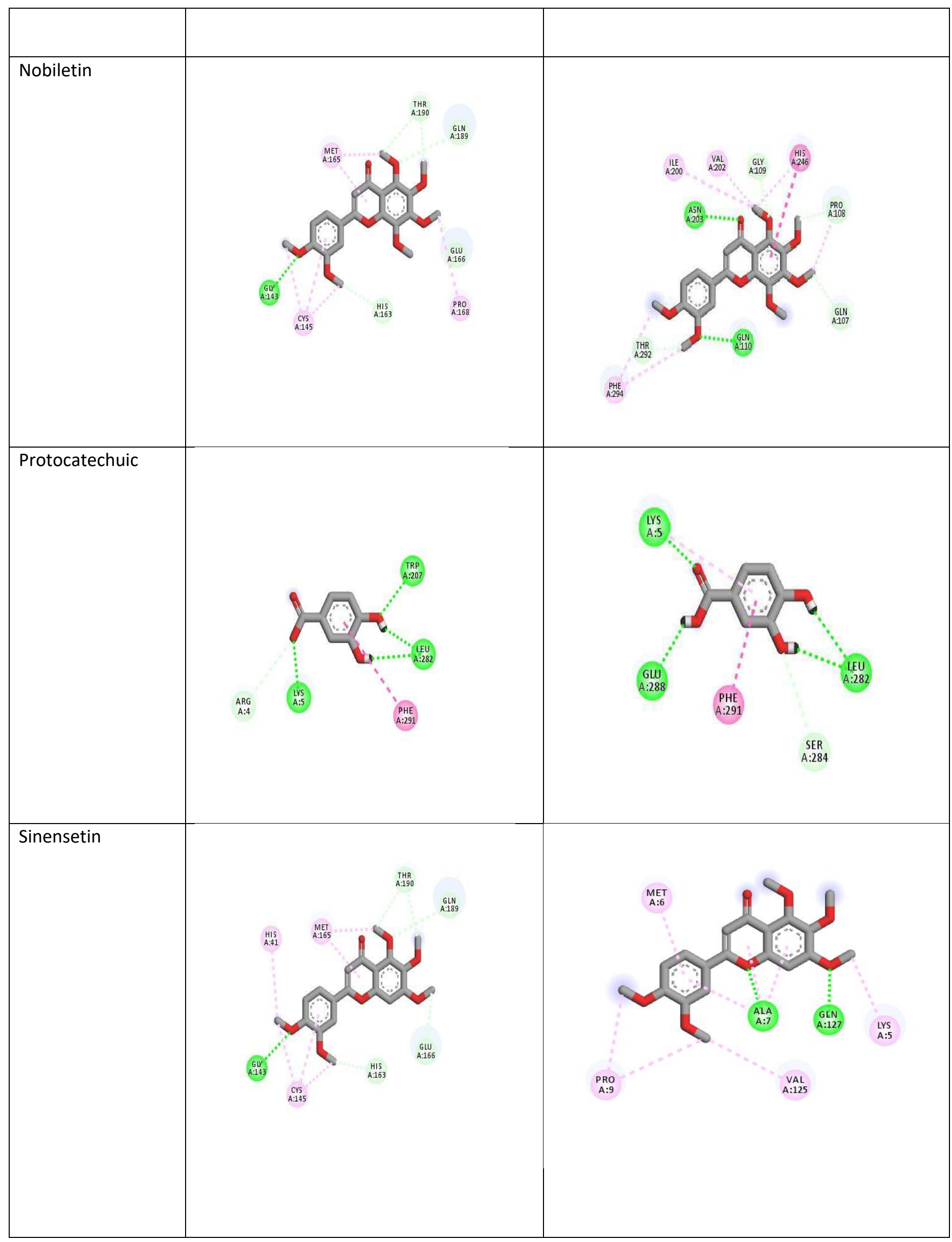




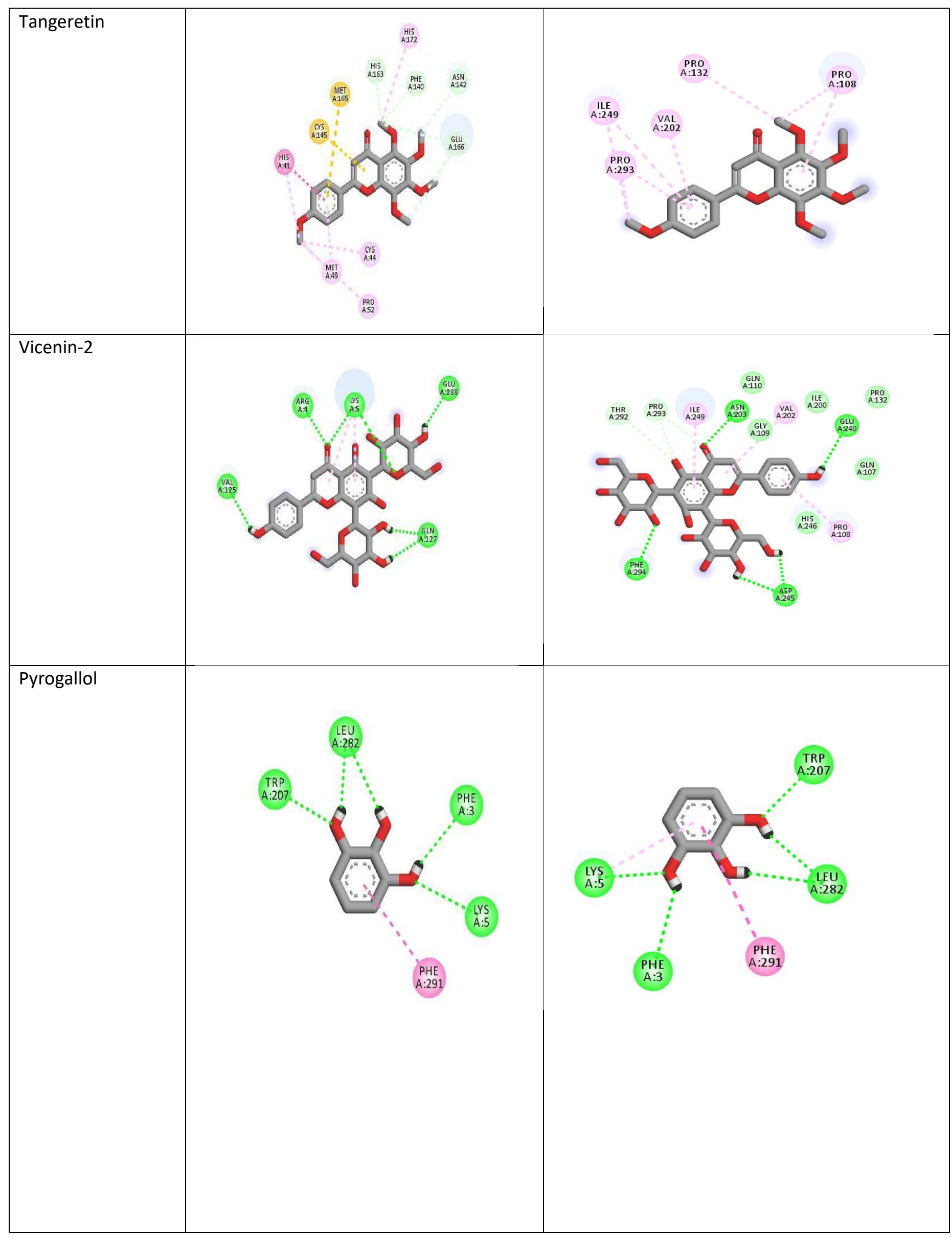




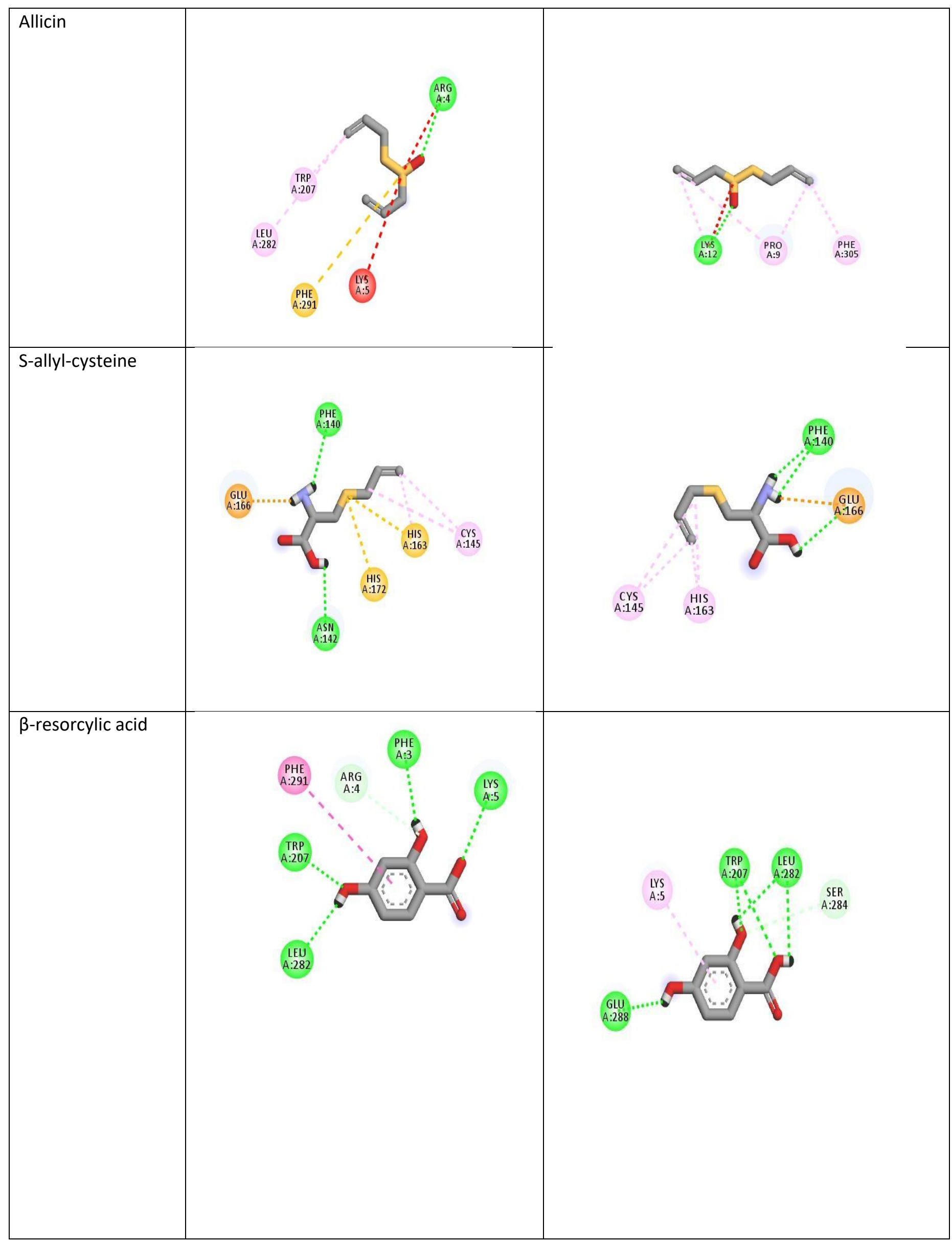




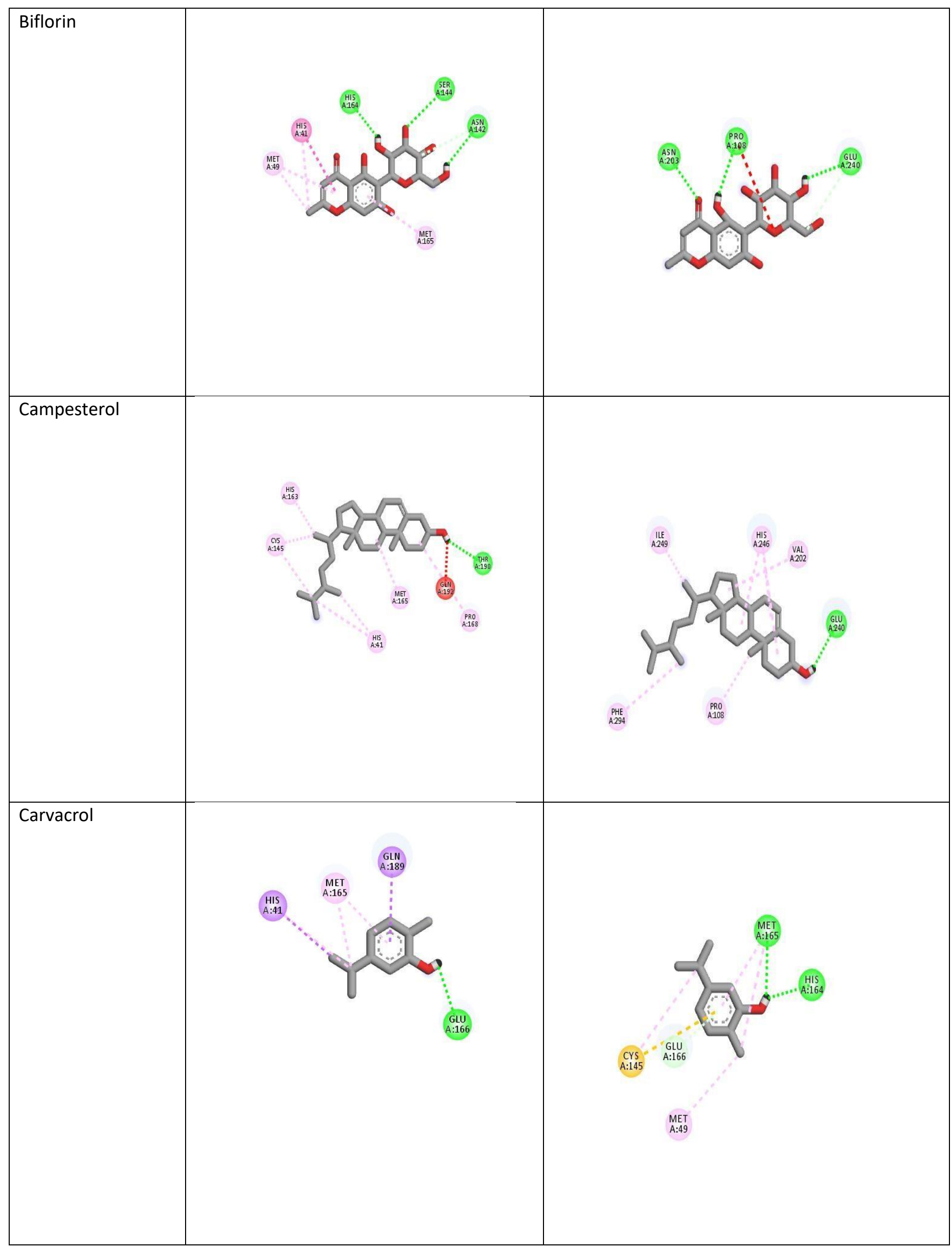




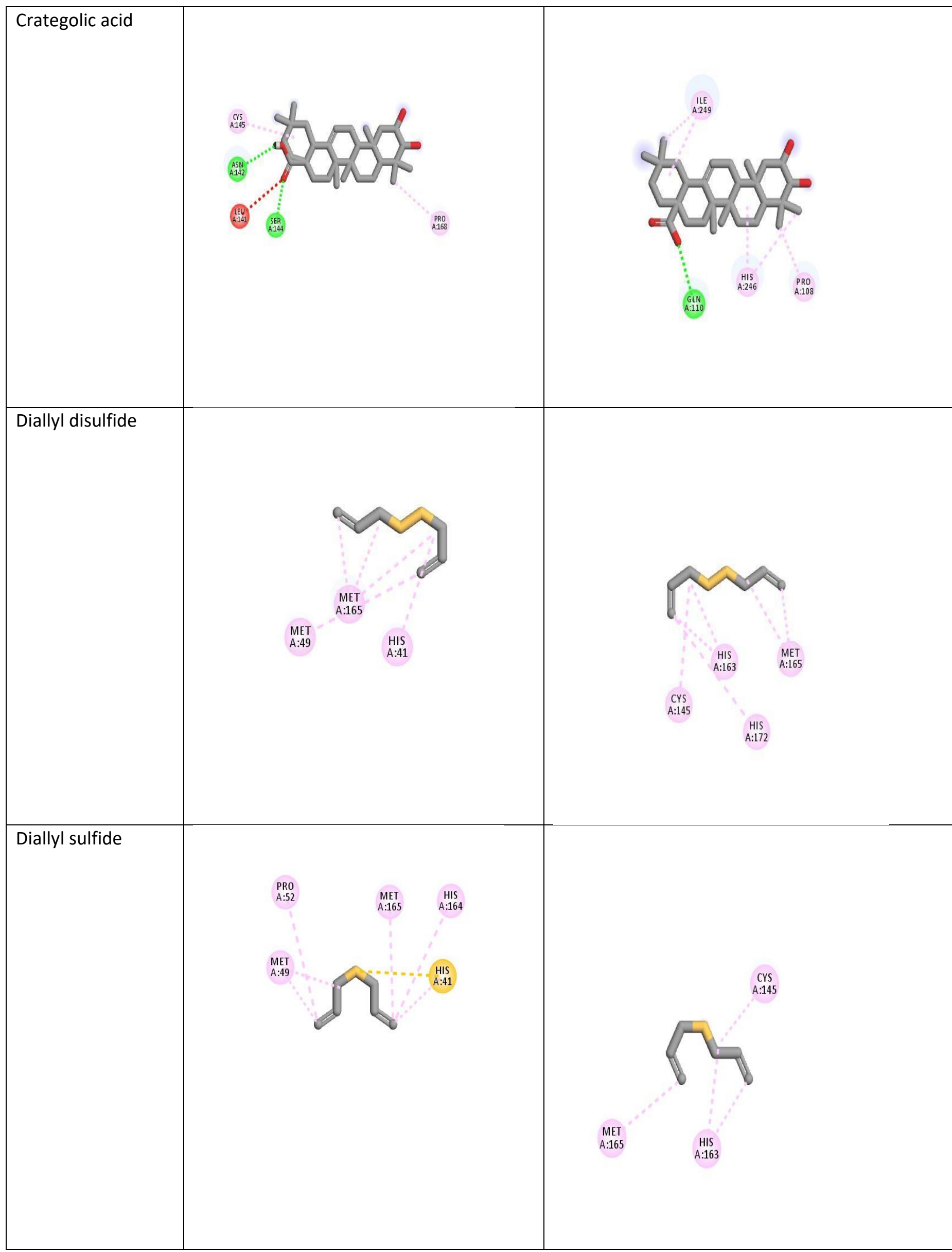




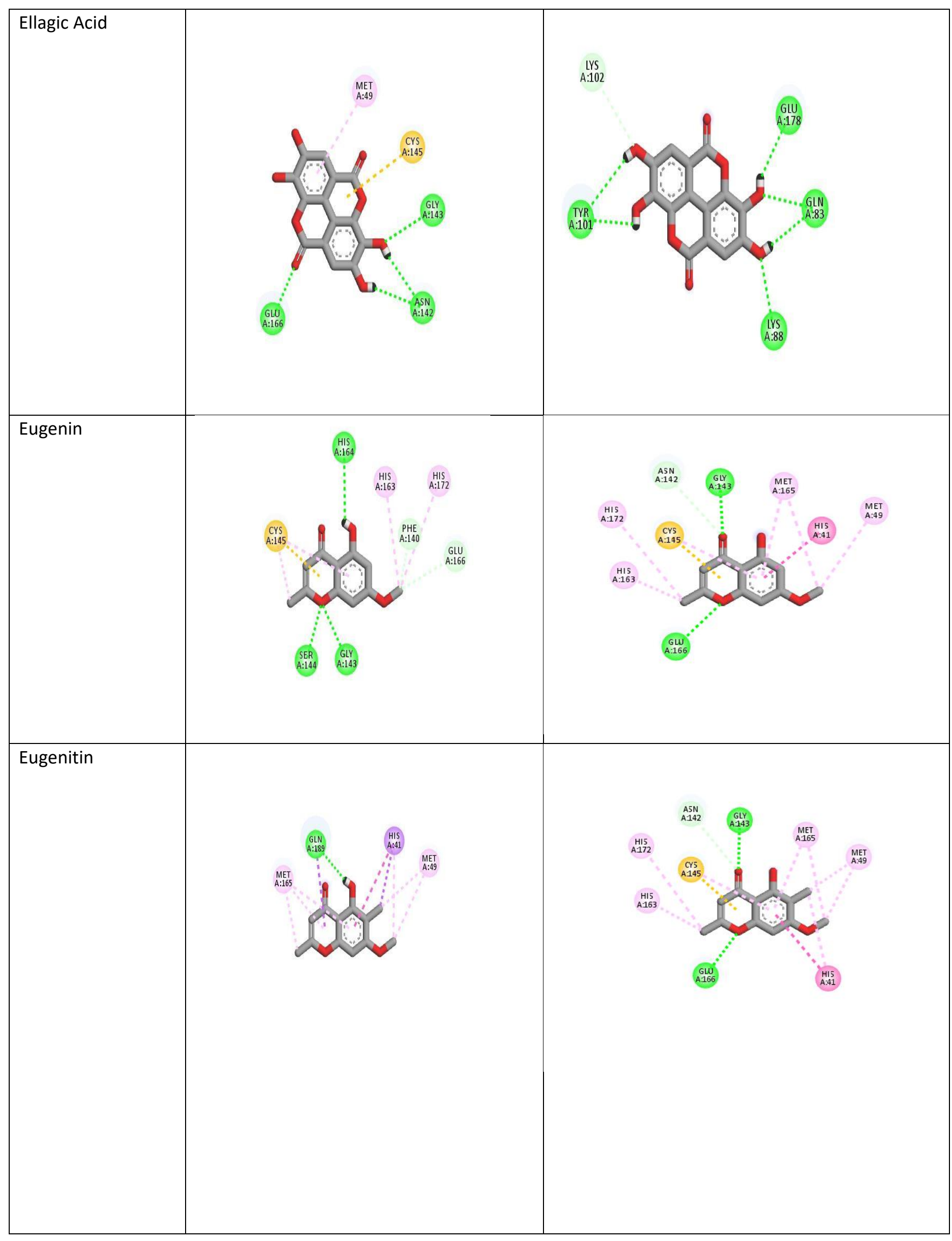




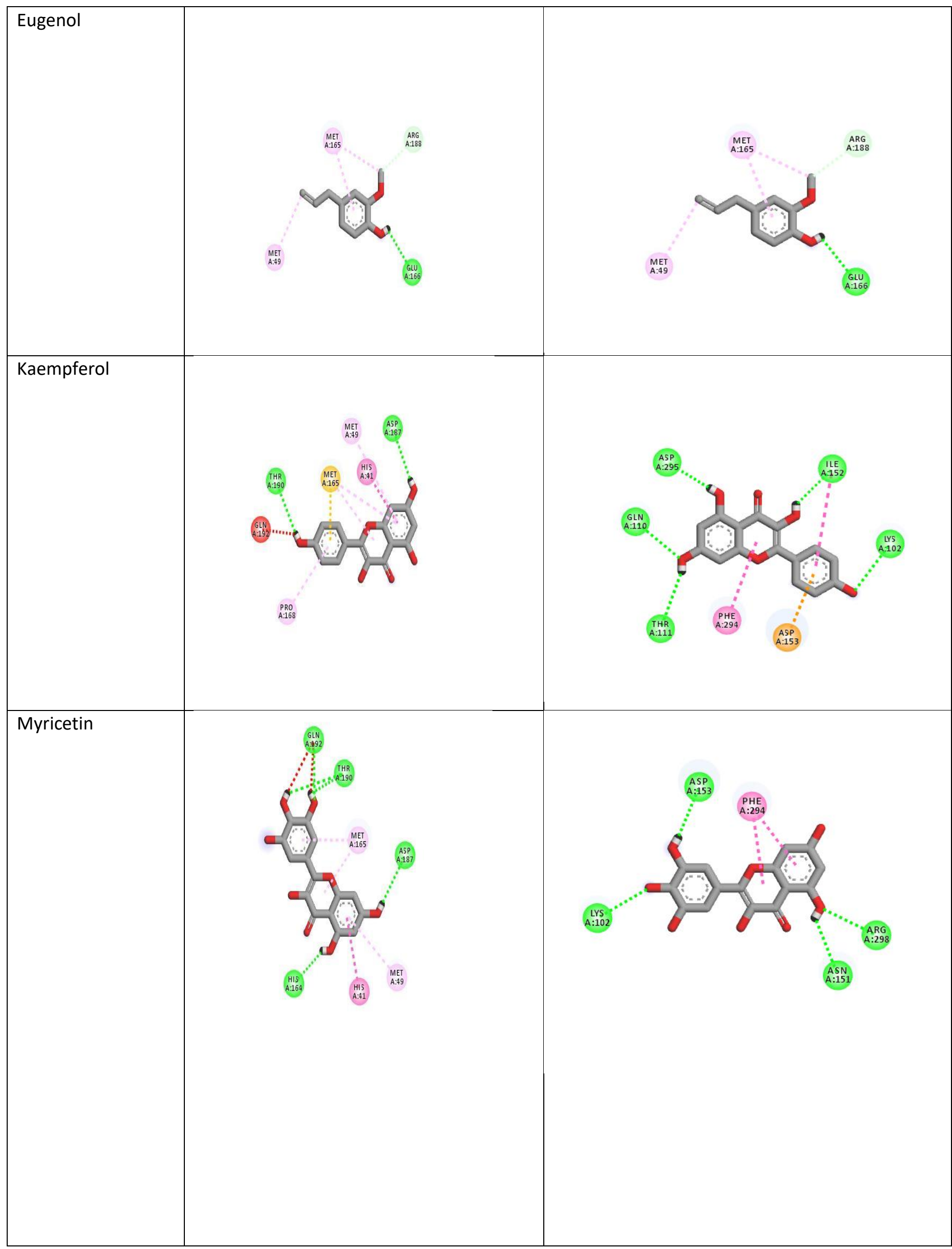




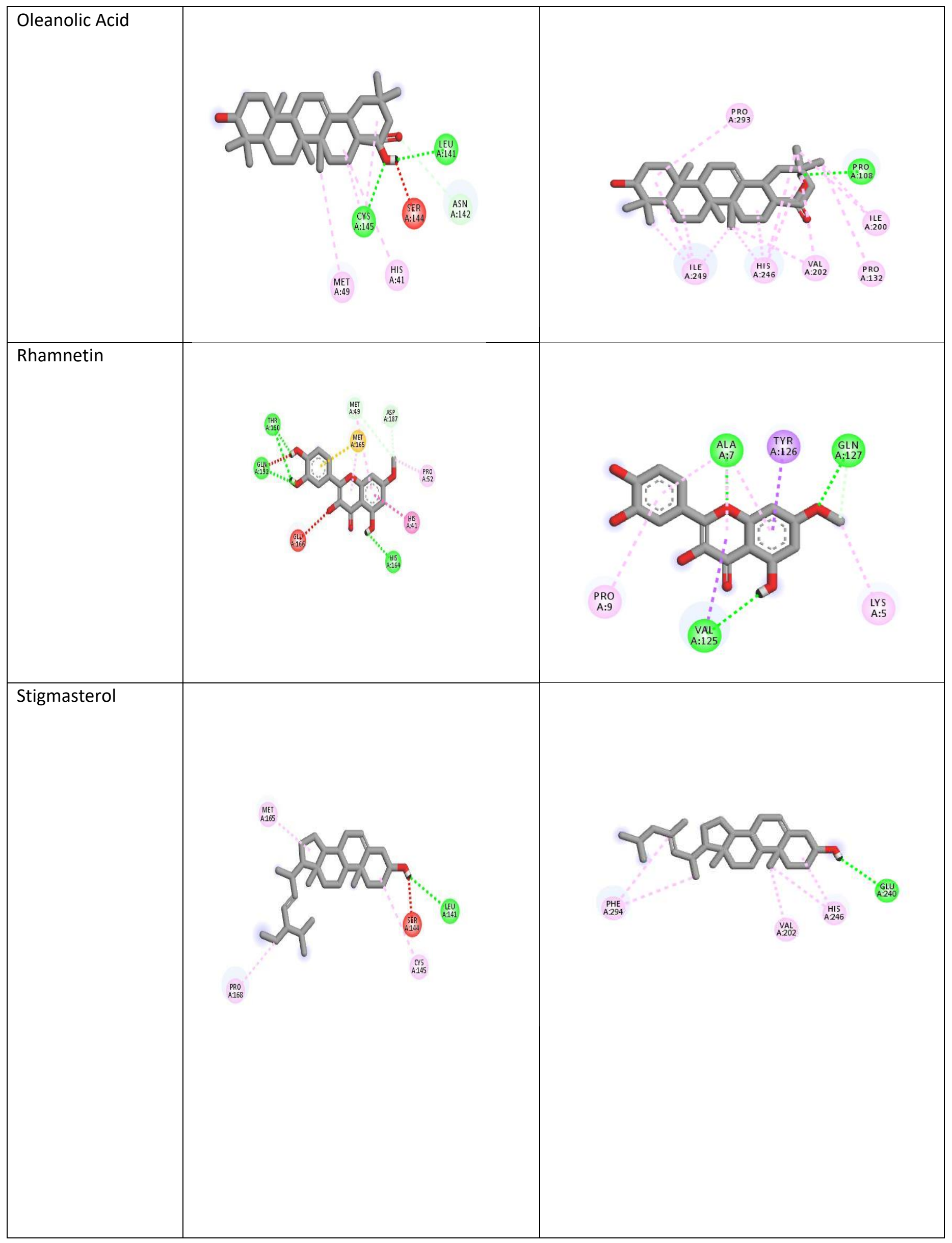




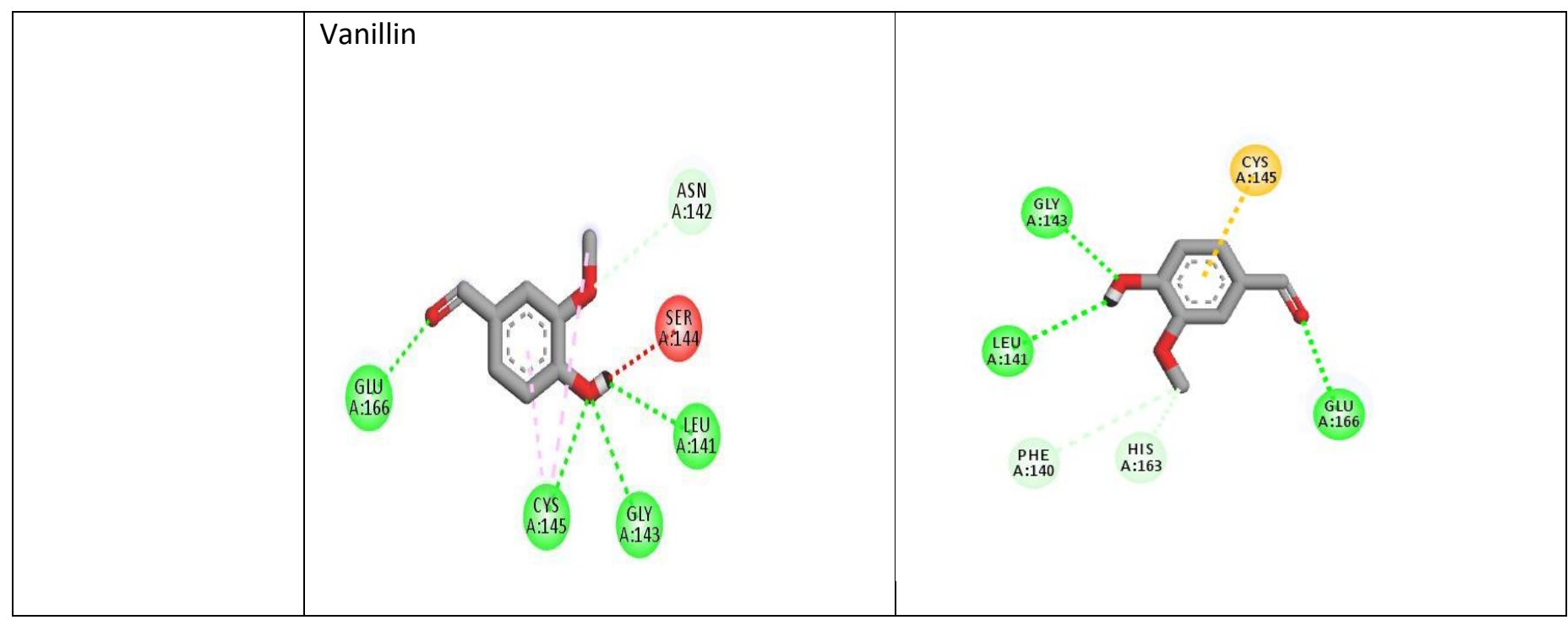

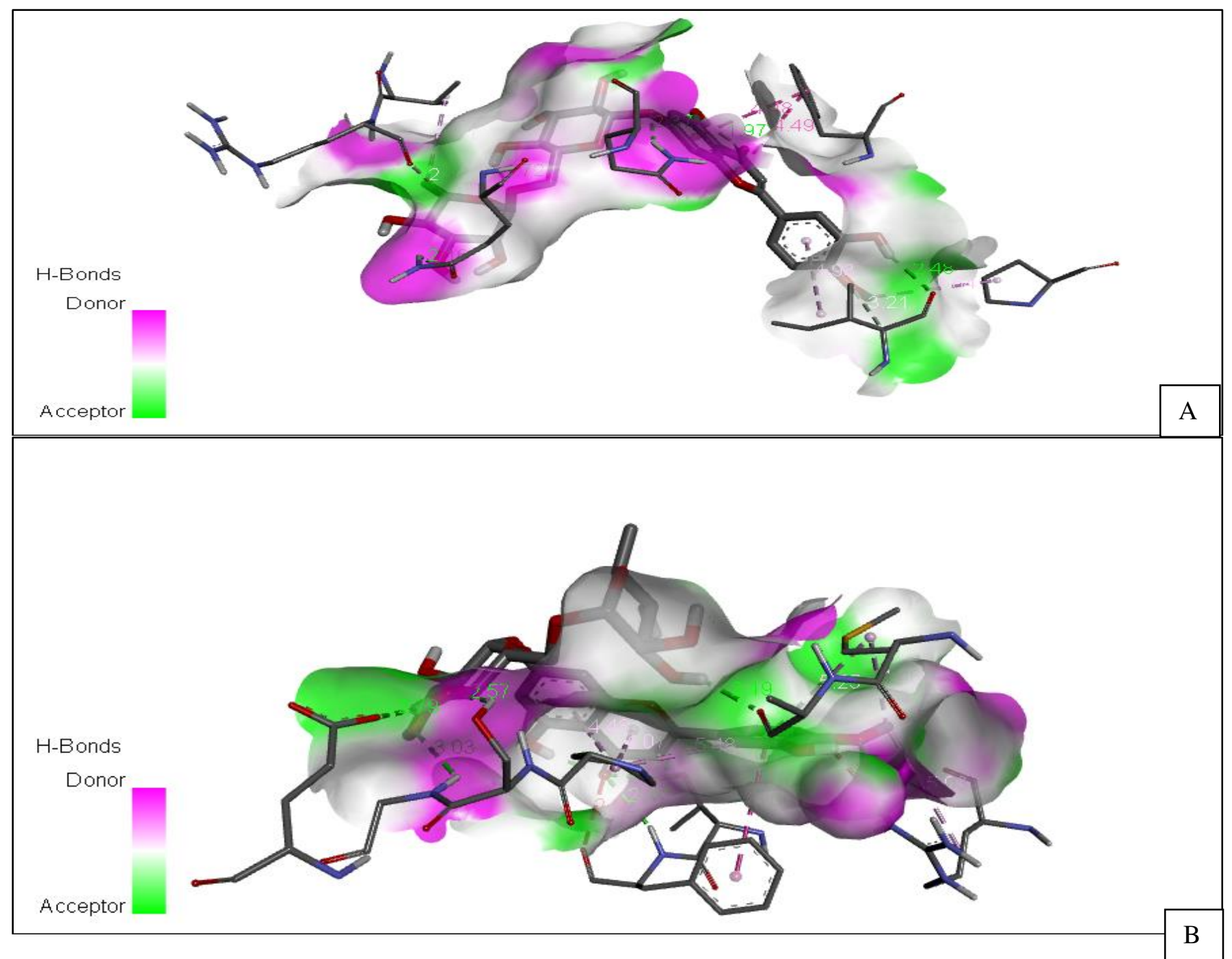

Figure 2: 3D View of the binding conformation of the diosmin inhibitor at 6LU7 protease (A) and 6Y2E protease (B) spike protein (Hydrogen Bond interaction) 


\subsection{MD simulation}

Simulations using the ReaxFF force field require a small timestep, so every bond break or formation is accurately observed. The aim of the simulations was to observe whether the ligand would bind to the protein, and which would be the energy variation of this process. Therefore, the behavior could be analyzed. Unit cells of the systems were built with the protein plus the ligand, with a minimum distance from each other of $20 \AA$, so after minimization, both would be kept in approximately the same place.

In all 4 cases, during production phase, the ligand succeeded in binding with the protein. The total energy of the system decreased significantly, showing a higher stabilization of the system with both structures bond together.

During the approach, the ligand structure suffered rotation, possibly due to the branches of the protein. Dipole/electrostatic interactions are constantly being evaluated during the simulations, so it is expected that the ligand (smaller structure) adapts to the protein surface for the most favorable bonding.

Figure 4 below presents the system $(61 u 7+$ hesperidin) from the beginning of the simulation to the complete binding of the ligand. In this specific case, the binding occurred at $80 \mathrm{ps}$ after the beginning, but was finished at approximately 120 ps from start.

As previously stated, hesperidin rotates before reaching the protein surface, and the approach becomes faster when the intermolecular interactions become stronger. The variation observed in the total energy of the system was approximately $\Delta \mathrm{E}=-11695.5 \mathrm{~kJ} / \mathrm{mol}$. Figure 3 presents the energy variation over time for this case.

Highest energy variation occurs in the first $25 \mathrm{ps}$. As the system was minimized at $5 \mathrm{~K}$, and then kept at $200 \mathrm{~K}$ during the equilibration phase, there is a rearrangement of the structures when applying $298 \mathrm{~K}$ in the production phase, thus stabilizing the system with this new parameter. This behavior is expected and observed in all 4 cases simulated. 


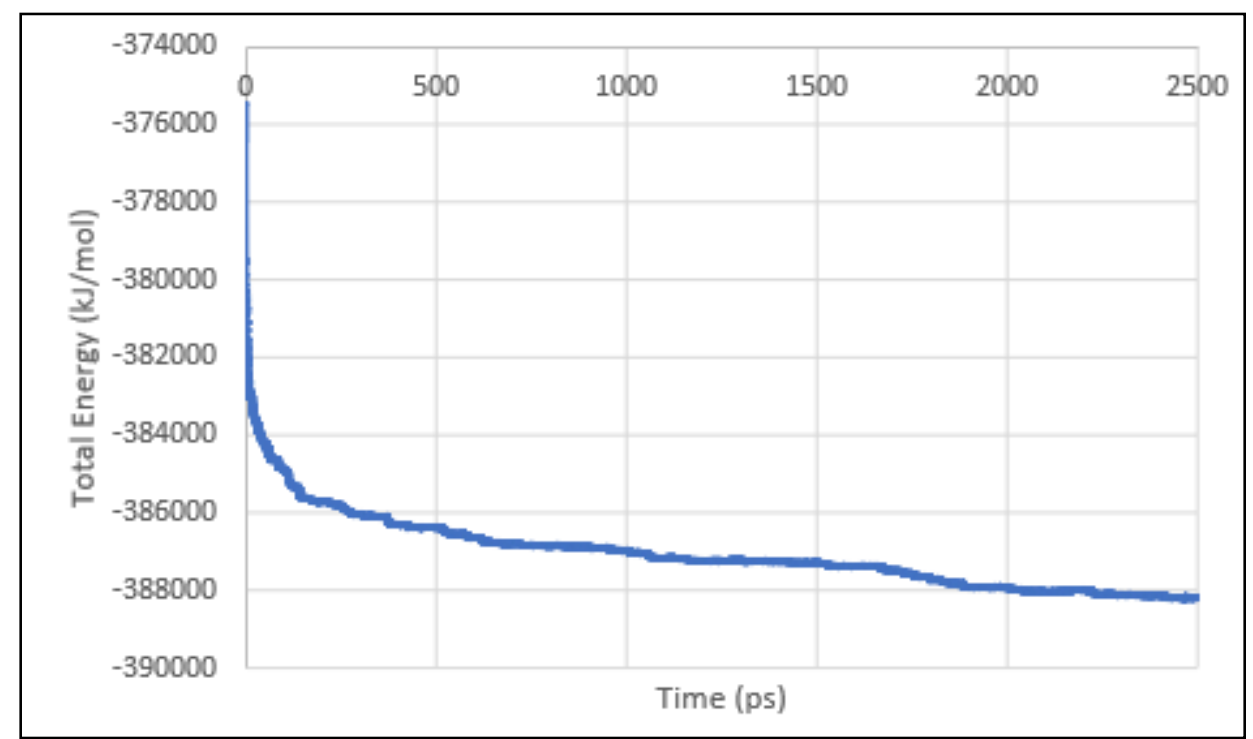

Figure 3. Total energy variation during the production phase of the RMD simulation for case 1

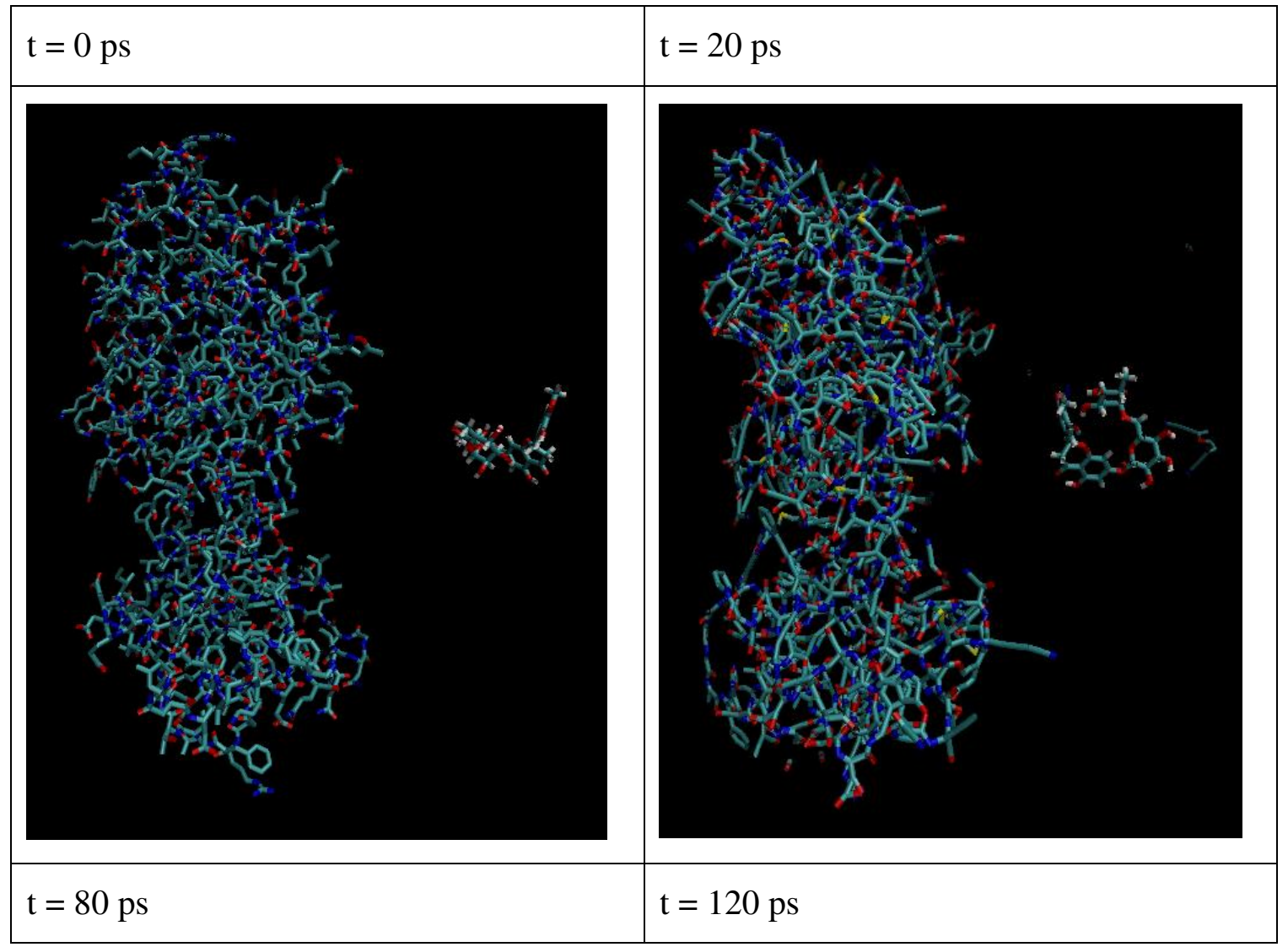




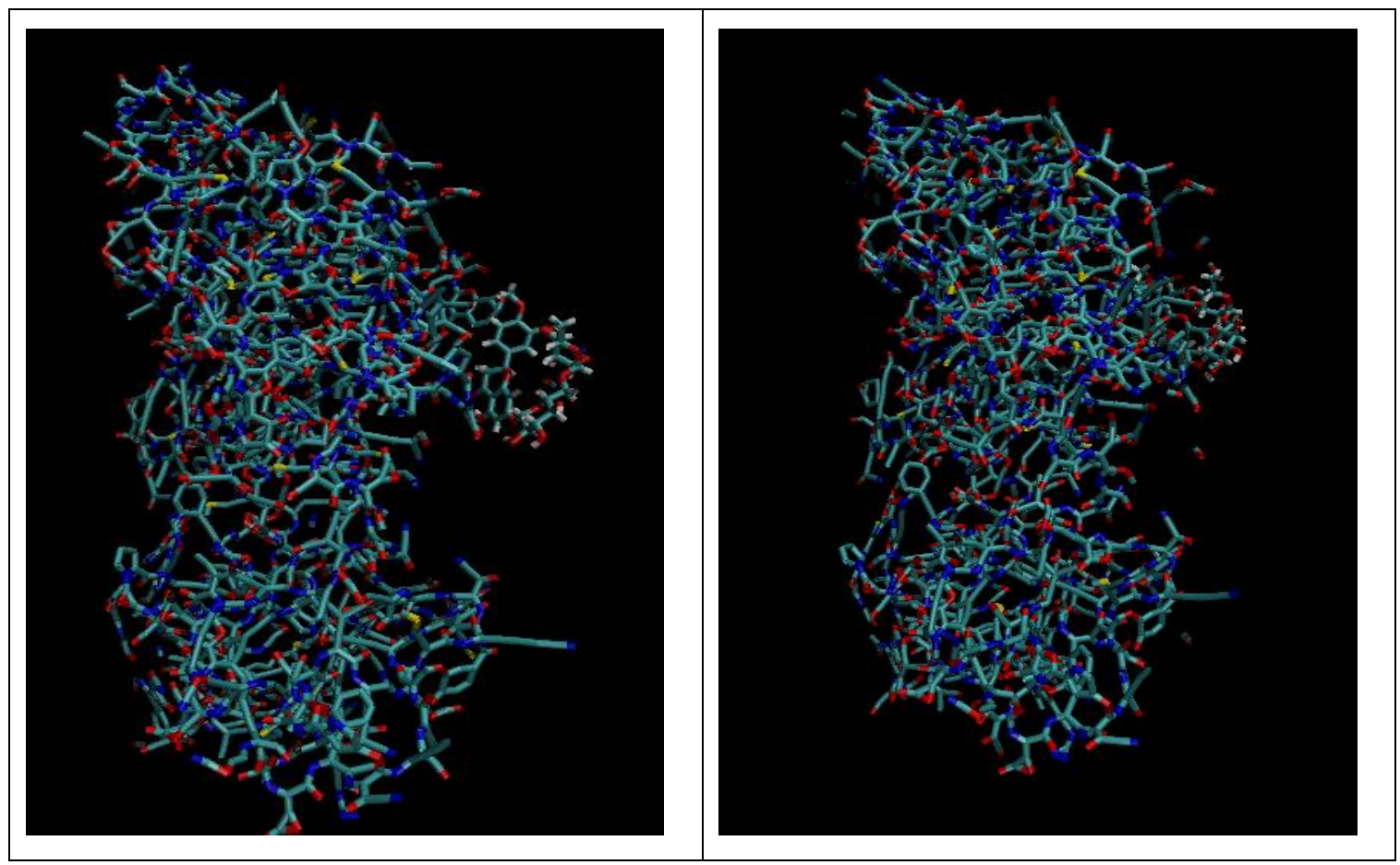

Figure 4. Time lapse of case 1, from the start to the complete biding of the ligand to the protein.

Hesperidin in contact with 6y2e (case 2) was much slower than in case 1 . After 120 ps from the beginning of the production phase, the ligand was still approaching the protein structure. The binding process started at approximately 200 ps after the start, but took almost 300 ps to complete.

One could say that hesperidin has more affinity to 6lu 7 than to $6 y 2 \mathrm{e}$ due to the difference in velocities. However, the total energy variation (Fig. 5) of this simulation was $\Delta \mathrm{E}=-20495.7 \mathrm{~kJ} / \mathrm{mol}$, almost double of the one observed in case 1 .

Therefore, besides the kinetics may be slower, the interaction between hesperidin and 6y2e is much stronger than with 6lu7, which may result in a better performance of the ligand in deactivating the active site of the protein.

Figure 6 presents the frames of the system in different times after the start of the production phase. 


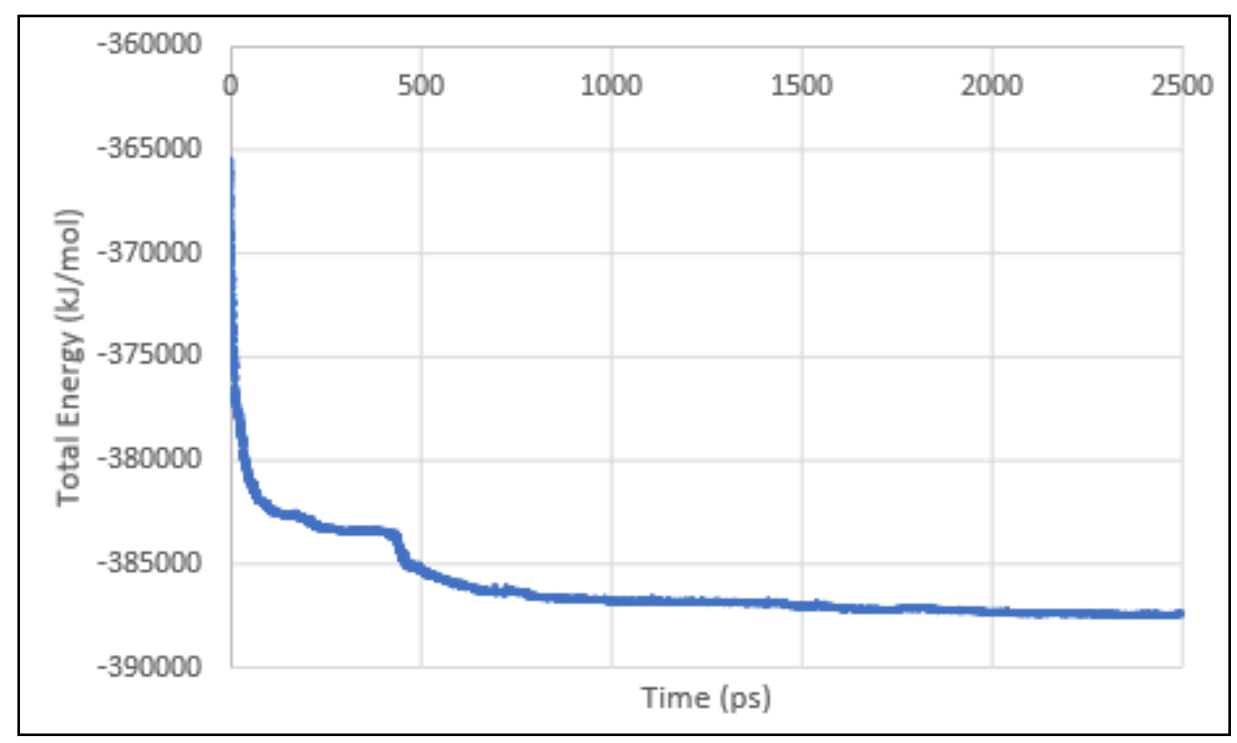

Figure 5. Total energy variation during the production phase of the RMD simulation for case 2

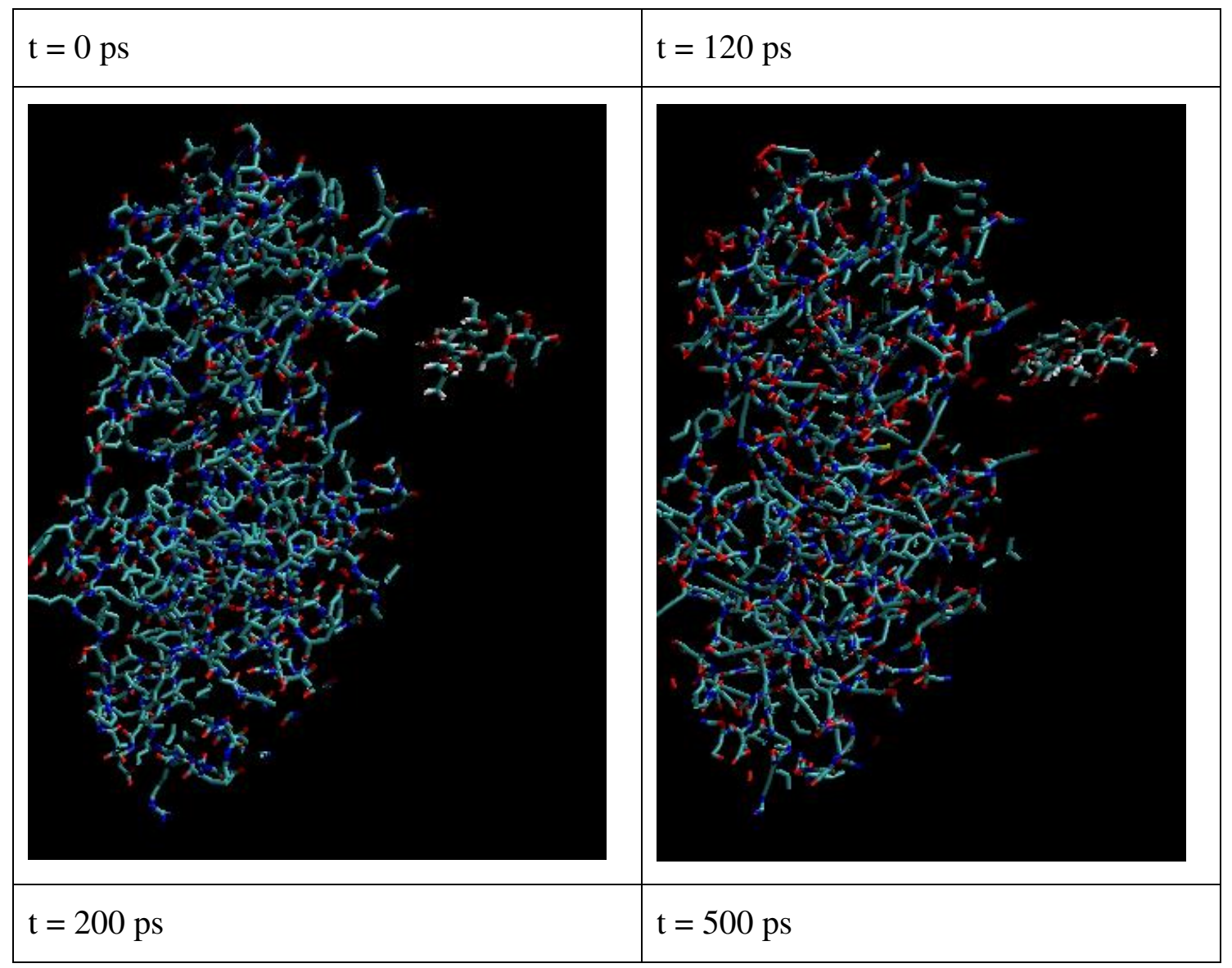




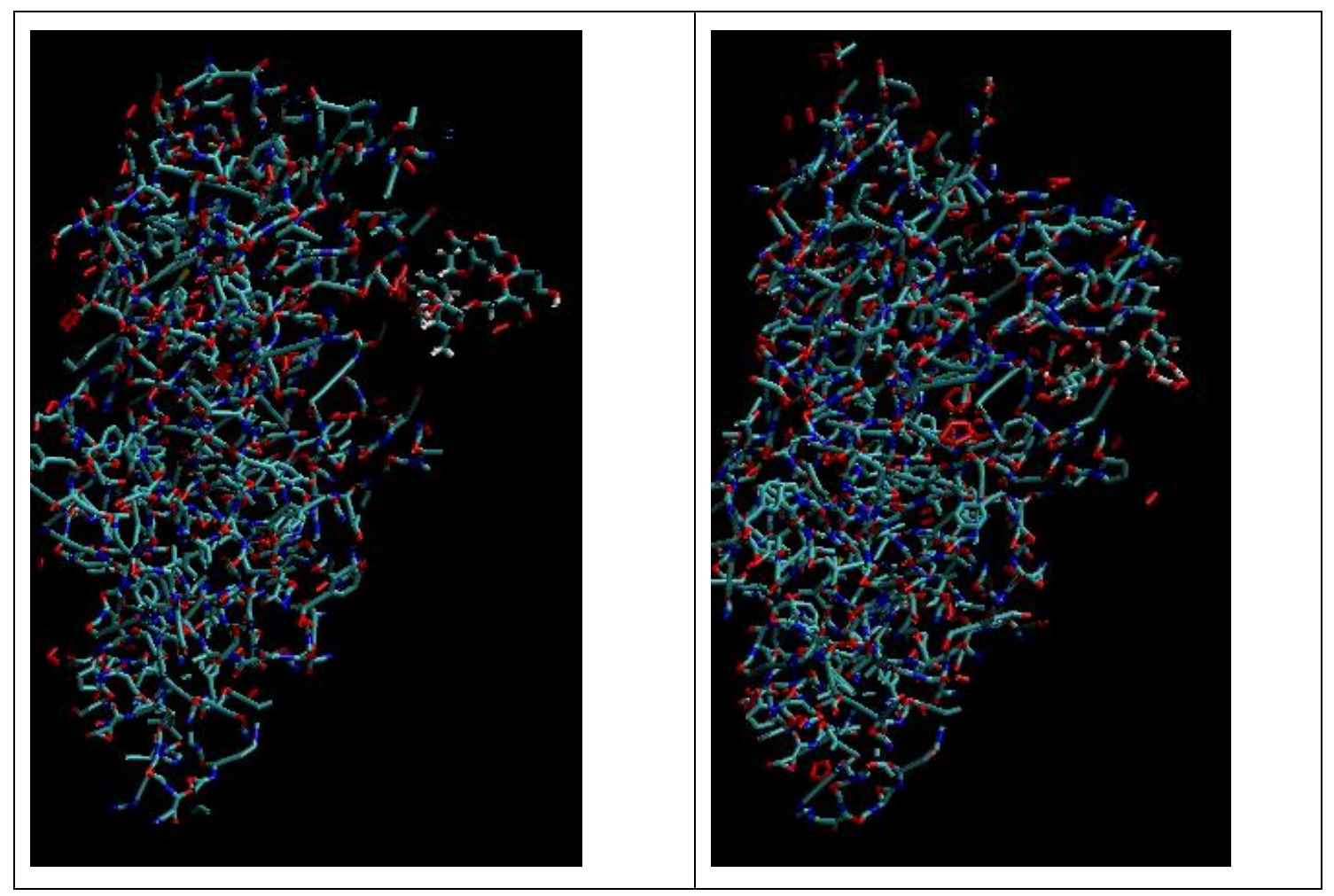

Figure 6. Time lapse of case 2, from the start to the complete biding of the ligand to the protein.

Cases 3 and 4 evaluate the behavior of Diosmin when in contact with $6 l u 7$ and 6y2e, respectively. In case 3, the ligand took almost 100 ps to approach and interact with the protein structure. After the initial interaction, only after 400 ps from the beginning of the production phase, the ligand was completely bound to the protein surface (Fig. 7).

An energy evaluation shows a difference of $\Delta \mathrm{E}=-12787.5 \mathrm{~kJ} / \mathrm{mol}$ from the beginning. The system becomes more stable, indicating a strong binding between protein and ligand (Fig. 8).

In comparison to case 1, 6lu7 shows a stronger binding with Hesperidin than with Diosmin, but as the difference is small $(\sim 10 \%)$, perhaps the kinetics presents a more important figure in this scenario. The complete bond of the ligand in case 3 is 3 times slower than in case 1, so possibly Hesperidin could be a more suitable ligand for protein 6lu7. 


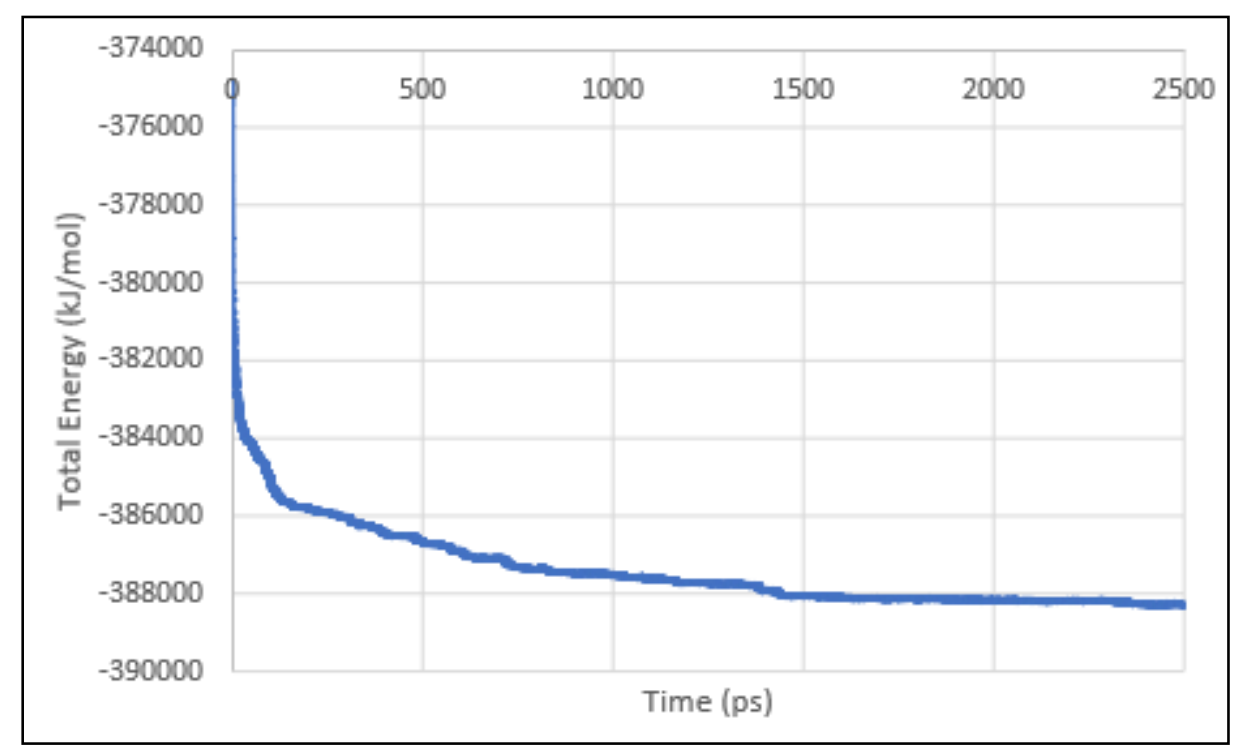

Figure 7. Total energy variation during the production phase of the RMD simulation for case 3

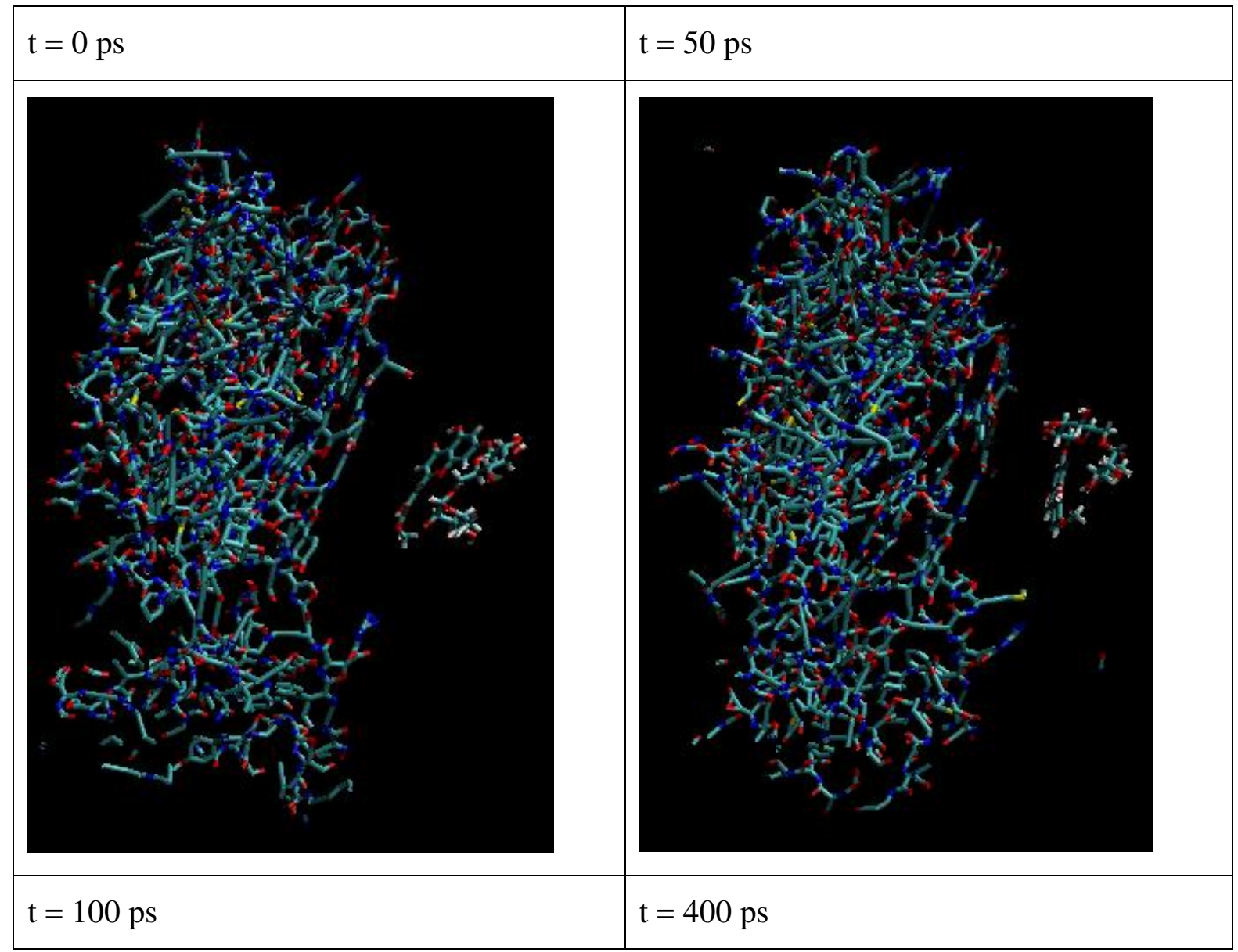




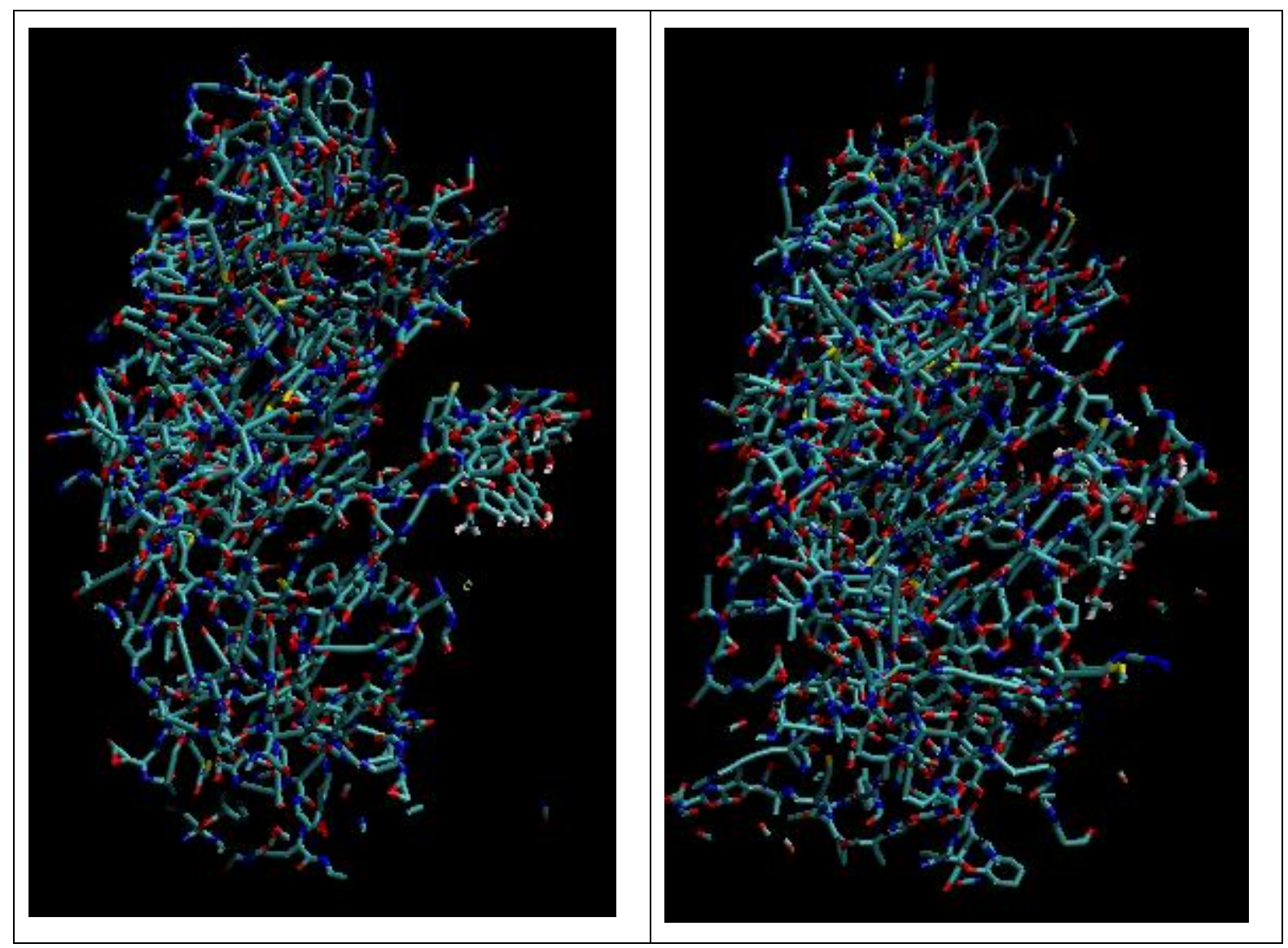

Figure 8 . Time lapse of case 3 , from the start to the complete biding of the ligand to the protein.

The last system evaluated was Diosmin + 6y2e (case 4). Among all system, this was the one with highest kinetics i.e., the approach of the ligand to the protein surface was the fastest. As observed in Fig. 9, after $35 \mathrm{ps}$ from the beginning of the production phase, the ligand was remarkably close to the protein 6y2e, showing a probable high interaction (dipole, Van der Waals etc.) between the structures. Some rearrangements (rotation) of Diosmin was observed, but after $200 \mathrm{ps,} \mathrm{the} \mathrm{ligand} \mathrm{was} \mathrm{completely} \mathrm{bound} \mathrm{to}$ the protein.

When comparing this system with case $2(6 y 2 e+$ Hesperidin), it is seen that the overall kinetics and energy (Fig. 10) of case 4 favors Diosmin as a more suitable ligand for protein 6y2e, with total energy variation of $\Delta \mathrm{E}=-21695 \mathrm{~kJ} / \mathrm{mol}$. Therefore, a faster coupling and a highest energy variation make this ligand the most favorable option for this protein. 


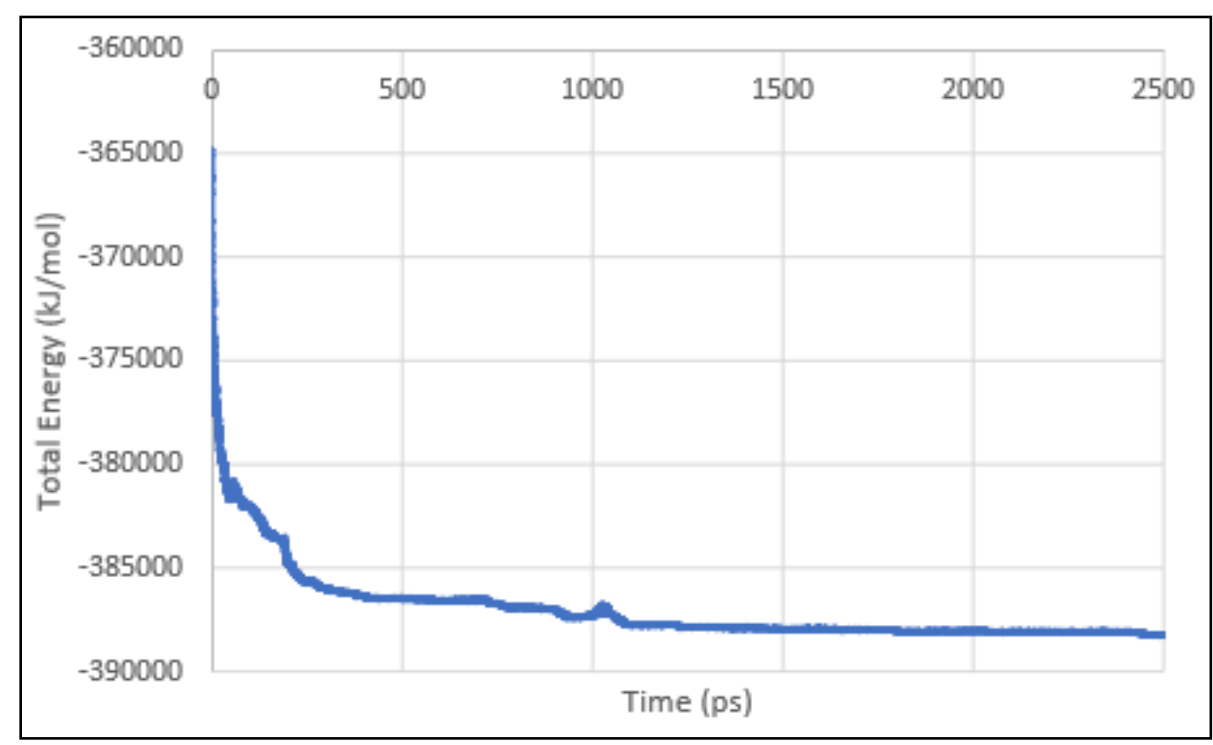

Figure 9. Total energy variation during the production phase of the RMD simulation for case 4

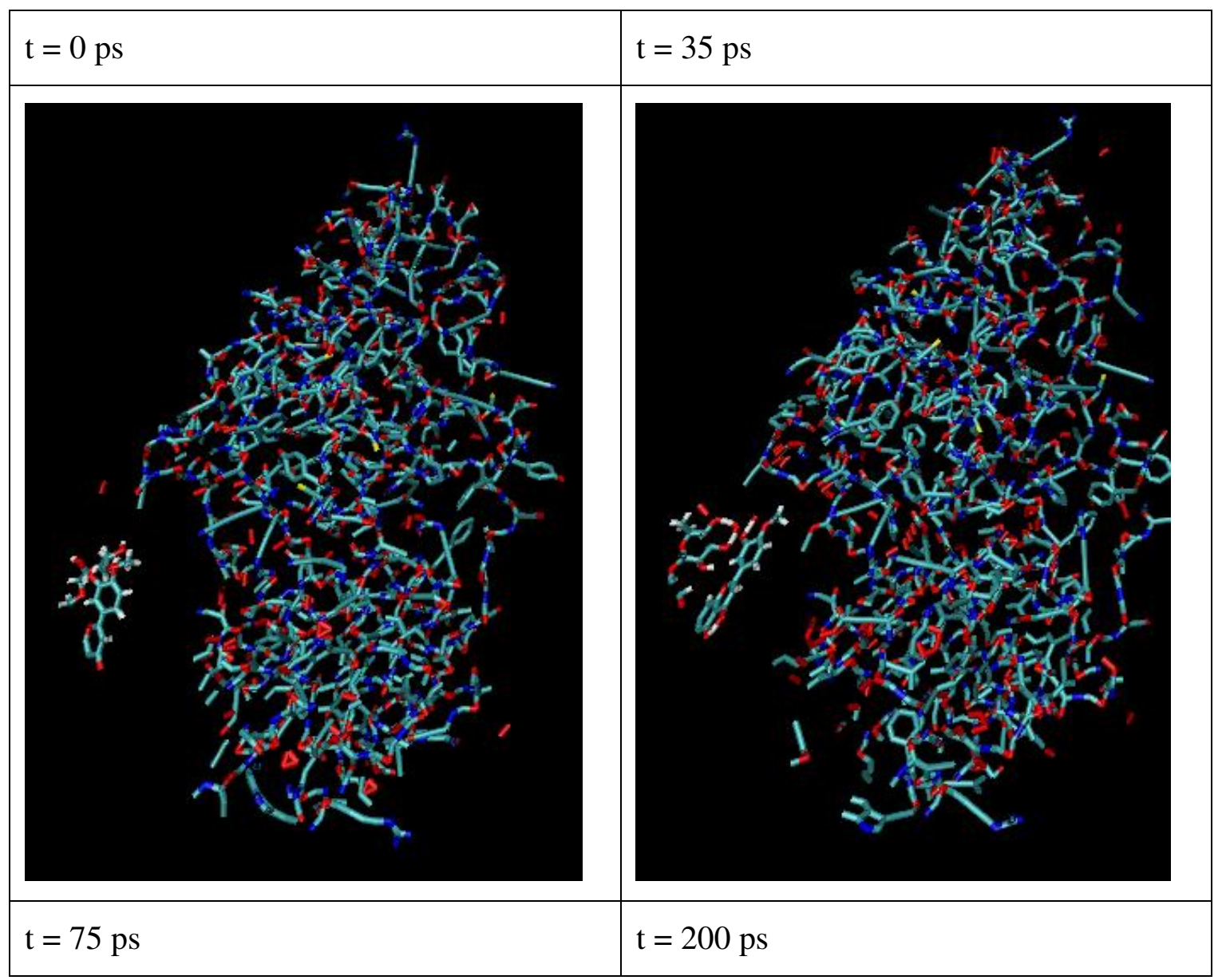




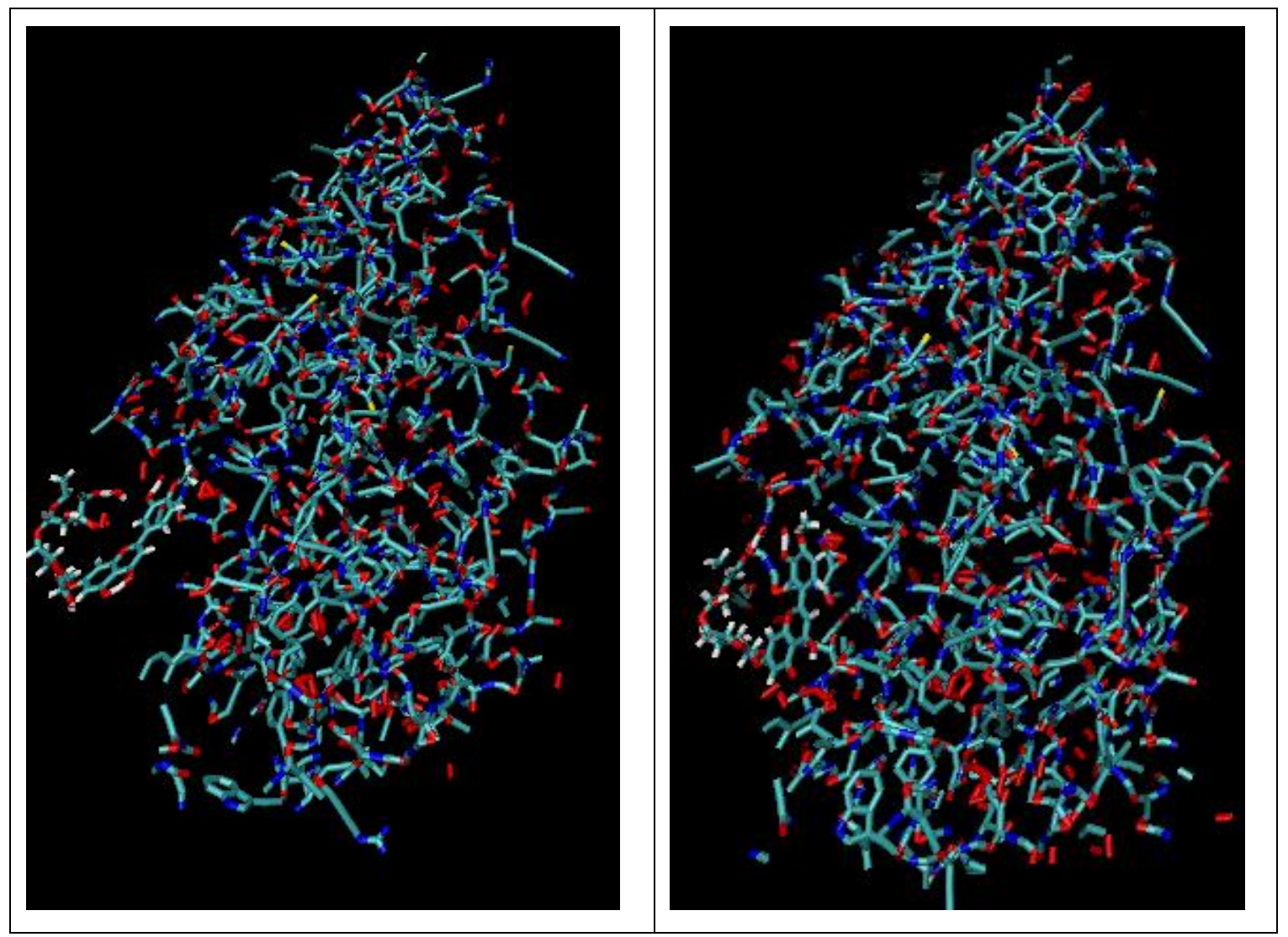

Figure 10. Time lapse of case 4, from the start to the complete biding of the ligand to the protein.

Conclusion

With the spread of the coronavirus in all countries of the world and in the absence of a vaccine or effective treatment to inhibit the infection, the use of plants takes a primordial place on the one hand in ethnobotanical use and on the other hand, by scientists to extract or synthesize molecules with inhibitory properties of SARS-COV-2. In our studies, we found that ellagic acid, narirutin, neoeriocitrin and neohesperidin are highly suggested as an inhibitor of SARS-COV-2.

\section{Compliance with ethical standards}

Conflicts of interest: The authors declare that there are no conflicts of interest.

Funding: No.

Consent to participate Not applicable.

Consent for publication Not applicable.

\section{Authors' contributions:}

Mohamed Chebaibi: Conceptualization, investigation, realization of molecular docking, Writing -Original

Draft 
Dalila Bousta: Conceptualization, Methodology, Data curation

Rene Francisco Boschi Gonçalves: Realization of molecular dynamics simulation

Hasnae Hoummani: Data curation

Sanae Achour: Conceptualization, Methodology, supervision.

\section{References}

Aanouz, I., Belhassan, A., El-Khatabi, K., Lakhlifi, T., El-Ldrissi, M., Bouachrine, M. (2020). Moroccan Medicinal plants as inhibitors against SARS-CoV-2 main protease: Computational investigations. Journal of Biomolecular Structure and Dynamics, 1-9.

Aboubakr, H.A., Nauertz, A., Luong, N.T., Agrawal, S., El-Sohaimy, S.A., Youssef, M.M., Goyal, S.M. (2016). In vitro antiviral activity of clove and ginger aqueous extracts against feline calicivirus, a surrogate for human norovirus. Journal of food protection, 79(6), 1001-1012.

Acquadro, S., Civra, A., Cagliero, C., Marengo, A., Rittà, M., Francese, R., Sanna, C., Bertea, C., Sgorbini, B., Lembo, D. (2020). Punica granatum Leaf Ethanolic Extract and Ellagic Acid as Inhibitors of Zika Virus Infection. Planta medica.

Aturki, Z., Brandi, V., Sinibaldi, M. (2004). Separation of flavanone-7-O-glycoside diastereomers and analysis in citrus juices by multidimensional liquid chromatography coupled with mass spectrometry. Journal of Agricultural and Food Chemistry, 52(17), 5303-5308.

Batiha, G.E.-S., Alkazmi, L.M., Wasef, L.G., Beshbishy, A.M., Nadwa, E.H., Rashwan, E.K. (2020). Syzygium aromaticum L.(Myrtaceae): Traditional uses, bioactive chemical constituents, pharmacological and toxicological activities. Biomolecules, 10(2), 202.

Bayan, L., Koulivand, P.H., Gorji, A. (2014). Garlic: a review of potential therapeutic effects. Avicenna journal of phytomedicine, $4(1), 1$.

Behbahani, M., Sayedipour, S., Pourazar, A., Shanehsazzadeh, M. (2014). In vitro anti-HIV-1 activities of kaempferol and kaempferol-7-O-glucoside isolated from Securigera securidaca. Research in pharmaceutical sciences, 9(6), 463.

Ben-Shabat, S., Yarmolinsky, L., Porat, D., Dahan, A. (2020). Antiviral effect of phytochemicals from medicinal plants: applications and drug delivery strategies. Drug Delivery and Translational Research, 1-14.

Care, C., Sornjai, W., Jaratsittisin, J., Hitakarun, A., Wikan, N., Triwitayakorn, K., Smith, D.R. (2020). Discordant Activity of Kaempferol Towards Dengue Virus and Japanese Encephalitis Virus. Molecules, 25(5), 1246.

Cortés-Rojas, D.F., de Souza, C.R.F., Oliveira, W.P. (2014). Clove (Syzygium aromaticum): a precious spice. Asian Pacific journal of tropical biomedicine, 4(2), 90-96.

Cui, Q., Du, R., Anantpadma, M., Schafer, A., Hou, L., Tian, J., Davey, R.A., Cheng, H., Rong, L. (2018). Identification of ellagic acid from plant Rhodiola rosea L. as an anti-Ebola virus entry inhibitor. Viruses, 10(4), 152.

de Vasconcellos, M.C., Bezerra, D.P., Fonseca, A.M., Pereira, M.R.P., Lemos, T.L.G., Pessoa, O.D.L., Pessoa, C., de Moraes, M.O., Alves, A.P.N.N., Costa-Lotufo, L.V. (2007). Antitumor activity of biflorin, an onaphthoquinone isolated from Capraria biflora. Biological and Pharmaceutical Bulletin, 30(8), 1416-1421.

Del Rıo, J., Fuster, M., Gómez, P., Porras, I., Garcıa-Lidón, A., Ortuño, A. (2004). Citrus limon: a source of flavonoids of pharmaceutical interest. Food Chemistry, 84(3), 457-461.

Dzubak, P., Hajduch, M., Vydra, D., Hustova, A., Kvasnica, M., Biedermann, D., Markova, L., Urban, M., Sarek, J. (2006). Pharmacological activities of natural triterpenoids and their therapeutic implications. Natural product reports, 23(3), 394-411.

Fenwick, G., Hanley, A. (1985). Allium species poisoning. Veterinary Record, 116(1), 28-28.

Hichri, F., Jannet, H.B., Cheriaa, J., Jegham, S., Mighri, Z. (2003). Antibacterial activities of a few prepared derivatives of oleanolic acid and of other natural triterpenic compounds. Comptes Rendus Chimie, 6(4), 473-483. 
Ikeda, T., Yokomizo, K., Okawa, M., Tsuchihashi, R., Kinjo, J., Nohara, T., Uyeda, M. (2005). Anti-herpes virus type 1 activity of oleanane-type triterpenoids. Biological and Pharmaceutical Bulletin, 28(9), 1779-1781.

Ismail, T., Calcabrini, C., Diaz, A.R., Fimognari, C., Turrini, E., Catanzaro, E., Akhtar, S., Sestili, P. (2016). Ellagitannins in cancer chemoprevention and therapy. Toxins, 8(5), 151.

Khaerunnisa, S., Kurniawan, H., Awaluddin, R., Suhartati, S., Soetjipto, S. (2020). Potential inhibitor of COVID-19 main protease (Mpro) from several medicinal plant compounds by molecular docking study. Prepr. doi10, 20944, 1-14.

Kim, S., Lee, H., Lee, S., Yoon, Y., Choi, K.-H. (2015). Antimicrobial action of oleanolic acid on Listeria monocytogenes, Enterococcus faecium, and Enterococcus faecalis. PLoS One, 10(3), e0118800.

Kong, L., Li, S., Liao, Q., Zhang, Y., Sun, R., Zhu, X., Zhang, Q., Wang, J., Wu, X., Fang, X. (2013). Oleanolic acid and ursolic acid: Novel hepatitis C virus antivirals that inhibit NS5B activity. Antiviral Research, 98(1), 44-53.

Mitrocotsa, D., Mitaku, S., Axarlis, S., Harvala, C., Malamas, M. (2000). Evaluation of the antiviral activity of kaempferol and its glycosides against human cytomegalovirus. Planta medica, 66(04), 377-379.

Moktar, A., Ravoori, S., Vadhanam, M.V., Gairola, C.G., Gupta, R.C. (2009). Cigarette smoke-induced DNA damage and repair detected by the comet assay in HPV-transformed cervical cells. International journal of oncology, 35(6), 1297-1304.

Montenegro, R.C., Burbano, R.R., Silva, M., Lemos, T.G., Vasconcellos, M.C. (2013). Biflorin, a naphthoquinone, inhibitsegfr in breast cancer cells. Med. Chem, 3, 179-182.

Narayanan, B.A., Geoffroy, O., Willingham, M.C., Re, G.G., Nixon, D.W. (1999). p53/p21 (WAF1/CIP1) expression and its possible role in $\mathrm{G} 1$ arrest and apoptosis in ellagic acid treated cancer cells. Cancer letters, 136(2), 215-221.

Ovesná, Z., Kozics, K., Slameňová, D. (2006). Protective effects of ursolic acid and oleanolic acid in leukemic cells. Mutation Research/Fundamental and Molecular Mechanisms of Mutagenesis, 600(1-2), 131-137.

Park, S.W., Kwon, M.J., Yoo, J.Y., Choi, H.-J., Ahn, Y.-J. (2014). Antiviral activity and possible mode of action of ellagic acid identified in Lagerstroemia speciosa leaves toward human rhinoviruses. BMC complementary and alternative medicine, 14(1), 171.

Petronelli, A., Pannitteri, G., Testa, U. (2009). Triterpenoids as new promising anticancer drugs. Anti-cancer drugs, 20(10), 880-892.

Pollier, J., Goossens, A. (2012). Oleanolic acid. Phytochemistry, 77, 10-15.

Saleem, H.N., Batool, F., Mansoor, H.J., Shahzad-ul-Hussan, S., Saeed, M. (2019). Inhibition of Dengue Virus Protease by Eugeniin, Isobiflorin, and Biflorin Isolated from the Flower Buds of Syzygium aromaticum (Cloves). Acs Omega, 4(1), 1525-1533.

Schwarz, S., Sauter, D., Wang, K., Zhang, R., Sun, B., Karioti, A., Bilia, A.R., Efferth, T., Schwarz, W. (2014). Kaempferol derivatives as antiviral drugs against the 3a channel protein of coronavirus. Planta medica, 80(02-03), 177.

Sharma, A., Tendulkar, A.V., Wangikar, P.P. (2011). Drug discovery against H1N1 virus (influenza A virus) via computational virtual screening approach. Medicinal Chemistry Research, 20(9), 1445-1449.

Shin, D., Mukherjee, R., Grewe, D., Bojkova, D., Baek, K., Bhattacharya, A., Schulz, L., Widera, M., Mehdipour, A.R., Tascher, G. (2020). Papain-like protease regulates SARS-CoV-2 viral spread and innate immunity. Nature, 1-10.

Somova, L., Shode, F., Ramnanan, P., Nadar, A. (2003). Antihypertensive, antiatherosclerotic and antioxidant activity of triterpenoids isolated from Olea europaea, subspecies africana leaves. Journal of ethnopharmacology, 84(2-3), 299-305.

Sultana, N., Ata, A. (2008). Oleanolic acid and related derivatives as medicinally important compounds. Journal of enzyme inhibition and medicinal chemistry, 23(6), 739-756.

Tsai, Y., Cole, L.L., Davis, L.E., Lockwood, S.J., Simmons, V., Wild, G.C. (1985). Antiviral properties of garlic: in vitro effects on influenza B, herpes simplex and coxsackie viruses. Planta medica, 51(05), 460-461.

ul Qamar, M.T., Alqahtani, S.M., Alamri, M.A., Chen, L.-L. (2020). Structural basis of SARS-CoV-2 3CLpro and antiCOVID-19 drug discovery from medicinal plants. Journal of pharmaceutical analysis.

Weber, N.D., Andersen, D.O., North, J.A., Murray, B.K., Lawson, L.D., Hughes, B.G. (1992). In vitro virucidal effects of Allium sativum (garlic) extract and compounds. Planta medica, 58(05), 417-423. 
Yu, D., Sakurai, Y., Chen, C.-H., Chang, F.-R., Huang, L., Kashiwada, Y., Lee, K.-H. (2006). Anti-AIDS agents 69. Moronic acid and other triterpene derivatives as novel potent anti-HIV agents. Journal of medicinal chemistry, 49(18), 5462-5469.

Zhu, Y.-M., Shen, J.-K., Wang, H.-K., Cosentino, L.M., Lee, K.-H. (2001). Synthesis and anti-HIV activity of oleanolic acid derivatives. Bioorganic \& medicinal chemistry letters, 11(24), 3115-3118. 


\section{Supplementary Files}

This is a list of supplementary files associated with this preprint. Click to download.

- ga.jpg 